\title{
Método para a avaliação técnica da qualidade pós-ocupação de áreas de uso comum de habitações de interesse social
}

\author{
Method for the post-occupation technical evaluation of \\ the quality of social housing communal areas
}

\section{Pablo Andrés Rangel \\ Carlos Torres Formoso \\ Luciana Inês Gomes Miron \\ Márcia Elisa Soares Echeveste}

\section{Resumo}

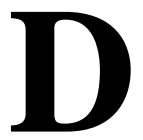

iversos programas habitacionais foram concebidos e implementados nas últimas décadas no Brasil, com o objetivo de reduzir o déficit habitacional. Apesar dos esforços para o desenvolvimento de habitação social, uma parcela substancial de empreendimentos tem apresentado falhas de qualidade ao longo da etapa de uso, as quais representam custos para a sociedade. Pesquisas anteriores têm concentrado suas avaliações nas unidades habitacionais, deixando como lacuna a avaliação dos espaços coletivos dos empreendimentos habitacionais de interesse social (EHIS). O presente trabalho propõe um método para a avaliação da qualidade das áreas de uso comum de EHIS. Por meio da abordagem metodológica Design Science Research, foram propostas ferramentas de coleta de dados e métricas para manifestações patológicas e não conformidades em áreas de uso comum. O método considera requisitos de normas técnicas relacionadas ao desempenho de edificações e acessibilidade, e delimita a avaliação a três elementos construtivos: fachadas de edifícios, calçadas e estacionamento, e áreas de circulação interna dos edifícios. O método foi testado em uma amostra de 10 EHIS na Região Metropolitana de Porto Alegre, RS, Brasil. A principal contribuição do trabalho está no desenvolvimento desse método para a avaliação pós-ocupação de áreas comuns, que permite a avaliação da qualidade técnica de forma rápida e padronizada.

1 Pablo Andrés Rangel Universidade Federal do Rio Grande do Sul Porto Alegre - RS - Brasil

${ }^{2}$ Carlos Torres Formoso Universidade Federal do Rio Grande do Sul

Porto Alegre - RS - Brasil

${ }^{3}$ Luciana Inês Gomes Miron Universidade Federal do Rio Grande Porto Alegre - RS - Brasil

${ }^{4}$ Márcia Elisa Soares Echeveste Universidade Federal do Rio Grande
Palavras-chave: Áreas comuns. Habitação de interesse social. Qualidade. Avaliação pós-ocupação.

\section{Abstract}

Several housing programs have been conceived and implemented in the last few decades in Brazil, with the aim to reduce the housing shortage. Despite the efforts to develop social housing, a substantial share of projects has had quality failures in the use phase, which represent costs to society. Previous research has been limited to the evaluation of housing units, leaving a gap in the evaluation of the communal areas of housing projects. This research study proposes a method to evaluate the quality of communal areas of social housing projects. By using Design Science Research as a methodological approach, tools for data collection and metrics for construction pathologies and non-conformities in communal areas were proposed. The method considers requirements of building performance and accessibility technical standards, and covers the evaluation to three elements of communal areas: building facades, sidewalks and parking spaces, and internal circulation areas of buildings. The method was tested on a sample of 10 social housing projects in the Metropolitan Region of Porto Alegre, RS, Brazil. The main contribution of this investigation is the development of the method for the evaluation of communal areas, which can be used to assess the technical quality of those areas in a fast and standardised way.

Keywords: Communal areas. Social Housing. Quality. Post-occupancy evaluation.

RANGEL, P. A.; FORMOSO, C. T.; MIRON, L. I. G.; ECHEVESTE, M. E. S. Método para a avaliação técnica da qualidade 171 pós-ocupação de áreas de uso comum de Habitações de Interesse Social. Ambiente Construído, Porto Alegre,

v. 20, n. 1, p. 171-194, jan./mar. 2020.

ISSN 1678-8621 Associação Nacional de Tecnologia do Ambiente Construído.

http:// dx. doi. org/ 10.1590/ s1678-862120200001003 


\section{Introdução}

A indústria da construção é frequentemente criticada por problemas de qualidade dos seus empreendimentos, inclusive no segmento de habitação de interesse social (ALEXANDRE, 2008; BRITO et al., 2011; BERR et al., 2015). Para Koskela (1992), a maioria dos problemas estão relacionados às falhas na gestão das diferentes fases de desenvolvimento dos empreendimentos. Em função do elevado grau de fragmentação das atividades, o mesmo autor também afirma que a identificação do erro consequente de uma determinada falha ocorre tardiamente. Segundo Del Mar (2013), muitos problemas de qualidade construtiva têm origem nas etapas de projeto e execução, sendo os seus principais impactos visíveis ao longo da etapa de uso e operação dos condomínios, resultando no surgimento de problemas vinculados às manifestações patológicas construtivas.

Entretanto, a falta de métodos padronizados para coletar dados sobre a qualidade construtiva dificulta a avaliação dos empreendimentos habitacionais na fase pós-ocupação (GEORGIOU, 2010; YUNG; YIP, 2010). Além disso, grande parte dos estudos sobre o tema se dedica às condições das unidades habitacionais (RICHTER, 2007; ALEXANDRE, 2008; BERR et al., 2015), de modo que as pesquisas sobre a qualidade dos espaços coletivos dos empreendimentos habitacionais ainda são incipientes (MARQUES, 2015).

Considerando a lacuna identificada, o presente trabalho propõe um método para a avaliação da qualidade técnica das áreas de uso comum de empreendimentos habitacionais de interesse social (EHIS), com base na qualidade construtiva e, particularmente, incidência de manifestações patológicas. Por área de uso comum entende-se todos os espaços coletivos dos EHIS, que pertencem ao condomínio de um edifício ou de um conjunto habitacional.

O método proposto foi delimitado em três elementos construtivos: calçadas e estacionamento, fachadas de edifícios, e áreas de circulação internas dos edifícios. Esses três elementos foram escolhidos após análises e discussões com síndicos, técnicos de órgãos públicos, especialistas e pesquisadores, conforme relatado no método de pesquisa, abaixo. Por ter foco na avaliação técnica, o método de proposto distingue-se de algumas avaliações pós-ocupação já realizadas, focadas no comportamento de uso e na percepção de usuários (BERR et al., 2015; MARQUES, 2015).

\section{Revisão bibliográfica}

Este item apresenta uma breve revisão bibliográfica sobre tópicos relevantes para a avaliação dos três elementos construtivos escolhidos para avaliação, incluindo os referenciais normativos sobre desempenho e acessibilidade, bem como as principais manifestações patológicas. Na primeira parte é apresentada a norma de desempenho NBR 15575 (ABNT, 2013a), o conceito da manutenção e a sua importância para os sistemas das edificações. Em sequência, são discutidos alguns requisitos da norma de acessibilidade NBR 9050 (ABNT, 2015) e os conceitos de rota acessível e livre mobilidade. Ao final do item, são apresentadas as manifestações patológicas mais comuns nas edificações de alvenaria estrutural, que é a tecnologia construtiva mais utilizada em EHIS no Sul do Brasil.

\section{Desempenho nas edificações}

Segundo Borges (2008), o desempenho pode ser entendido como as condições mínimas de habitabilidade necessárias para que os usuários possam utilizar uma edificação durante determinado período, podendo o desempenho variar de um usuário para o outro, dependendo das exigências e necessidades ou dos cuidados de cada um. Uma parte da responsabilidade pelo desempenho das edificações recai sobre os usuários, já que a realização das manutenções pertinentes afeta o futuro desempenho dessas edificações (BORGES, 2008). Dal Molin et al. (2016) destacam que, para garantir ou prolongar a vida útil do edifício, é importante, a realização da manutenção dos sistemas da edificação por parte dos usuários. Segundo Borges (2008), o construtor é o responsável pelo fornecimento de um manual para orientar os usuários e os administradores dos empreendimentos na realização da manutenção corretiva e preventiva nos sistemas das edificações entregues. Segundo a Norma de Desempenho NBR 15575 (ABNT, 2013a), o manual de uso, operação e manutenção é um documento que deve reunir as informações necessárias para orientar as atividades de uso, conservação e manutenção de uma edificação tanto das unidades autônomas como das áreas comuns. A Figura 1 apresenta a relação entre desempenho, vida útil e manutenção ao longo do tempo. A ausência ou falta de manutenção, especificada no manual de uso, operação e manutenção, afeta a qualidade da edificação devido à redução da vida útil, podendo causar envelhecimento precoce dos sistemas da edificação (ABNT, 2013a). 
Figura 1 - Relação entre desempenho, vida útil e manutenção ao longo do tempo

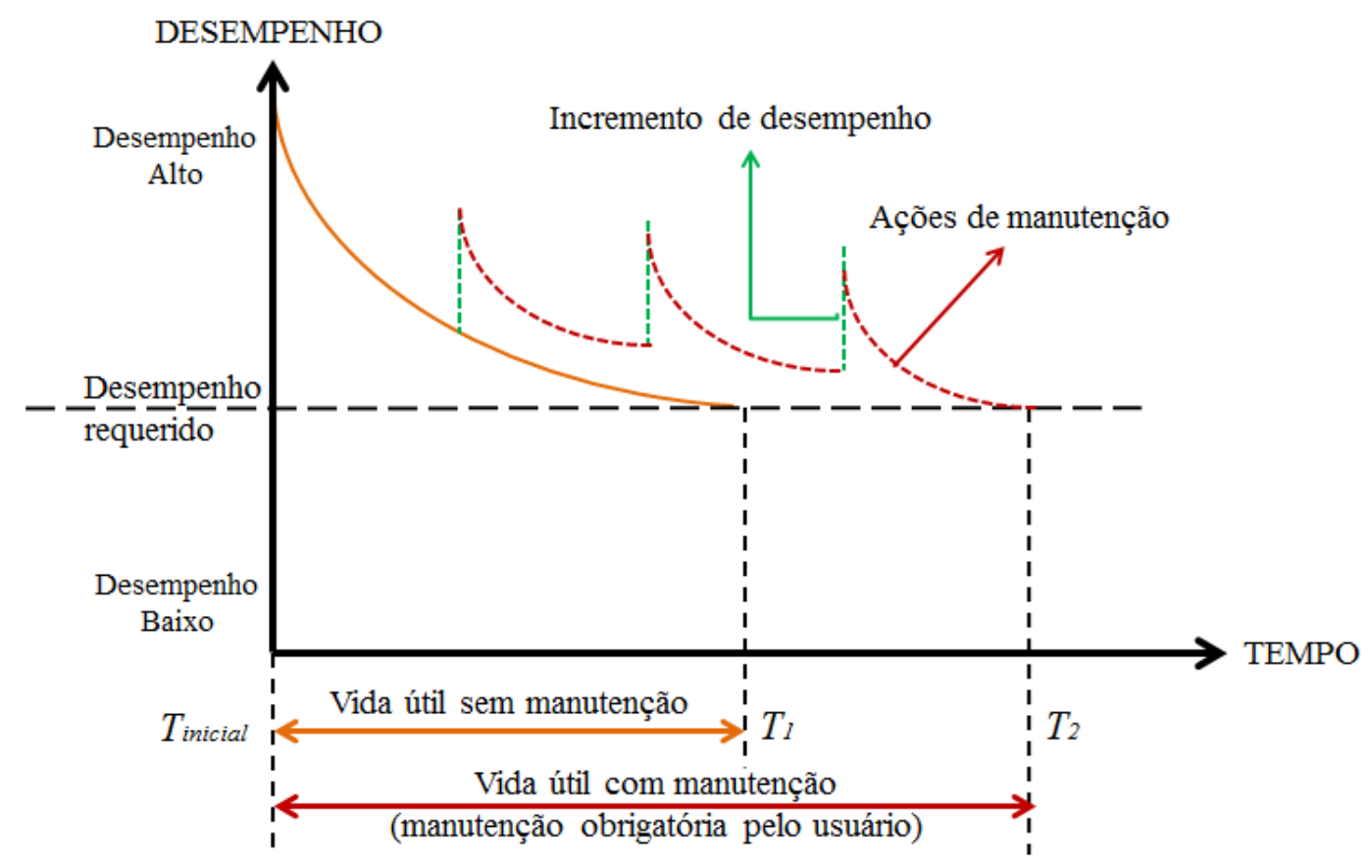

Fonte: adaptada de NBR 15575 (ABNT, 2013a).

\section{Acessibilidade em conjuntos habitacionais}

A norma brasileira NBR 9050 (ABNT, 2015) - Acessibilidade a edifícios, mobiliário, espaços e equipamentos urbanos - estabelece que os condomínios, edificações residenciais multifamiliares e conjuntos habitacionais devem ser acessíveis em todas as suas áreas de uso comum (ABNT, 2015). Segundo a mesma norma, a acessibilidade é um requisito fundamental que deve ser contemplada em todos os empreendimentos de construção existentes ou futuros. Para garantir esse requisito, todas as áreas de uso comum da edificação devem ser conectadas por meio de rotas acessíveis que facilitem o deslocamento de forma autônoma e segura possível à maioria dos indivíduos, especialmente às pessoas com mobilidade reduzida (PMR) (ABNT, 2015).

De acordo com Zanini (2017), a acessibilidade desempenha um papel fundamental para que haja igualdade social, de forma que todos os indivíduos possam utilizar os mesmos espaços. Em suma, trata-se de um direito de todos os moradores à livre mobilidade nessas áreas (ZANINI, 2017).

Uma rota acessível deve conectar os ambientes internos das edificações com suas áreas de uso comum de forma contínua, sem desníveis, sem obstáculos e bem sinalizado (ABNT, 2015). O piso da rota acessível deve ser composto por uma sinalização tátil e visual de forma direcional e de alerta, servindo de orientação principalmente às pessoas com deficiência visual (ABNT, 2015). Segundo a NBR 9050 (ABNT, 2015), o piso tátil direcional indica os caminhos preferenciais de circulação e deve ser instalado no sentido do deslocamento das pessoas, conforme a Figura 2. O piso tátil de alerta, por sua vez, informa desníveis, mudanças de direção, opções de percursos para os usuários ou situações de risco, como, por exemplo, o início e o término de degraus, escadas e rampas. Portanto, é importante que todos os acessos aos blocos ou prédios dos condomínios permaneçam livres de desníveis e obstáculos (ABNT, 2015). Esses acessos devem ser conectados aos demais ambientes da edificação, tais como estacionamentos, calçadas internas, salão de festas e áreas de lazer, por meio de rota acessível, para garantir que a circulação seja segura e confortável para todos os moradores do condomínio (ABNT, 2015). 
Figura 2 - Calçada com piso tátil direcional e de alerta em uma rota acessível

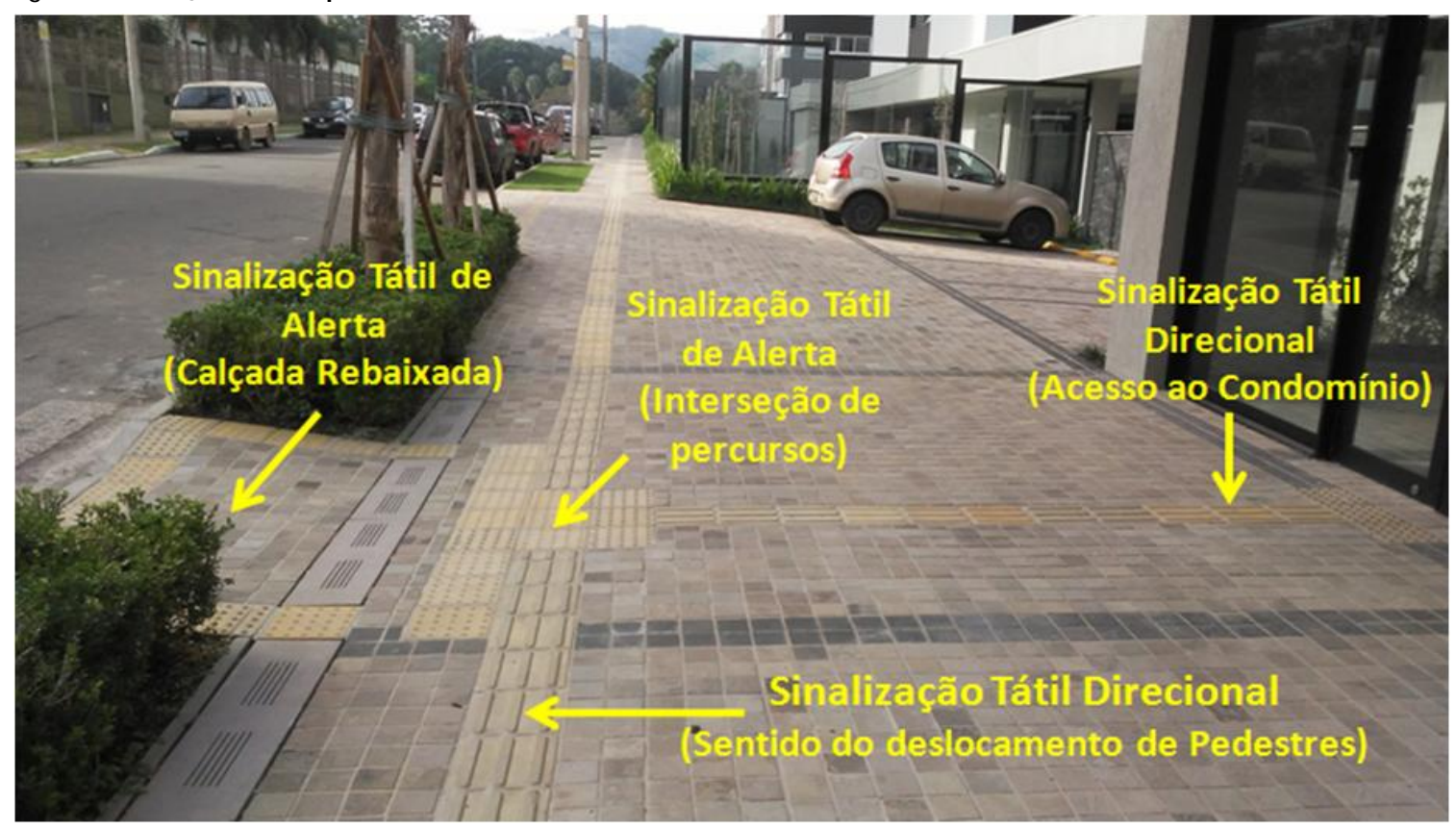

\section{Manifestações patológicas nas fachadas das edificações}

Existem inúmeras razões pelas quais a qualidade das edificações é afetada, causando envelhecimento precoce e aumentando os custos de reparo, manutenção e operação das mesmas (SEGAT, 2006; DAL MOLIN et al., 2016). Em função desses problemas de qualidade, surgem manifestações patológicas que podem deteriorar gradativamente tanto a estética quanto a segurança estrutural das edificações (DAL MOLIN et al., 2016). Essas manifestações podem causar desconforto e até mesmo comprometer a segurança dos usuários, em função da degradação que reduz o desempenho e, por conseguinte, a vida útil da edificação (SEGAT, 2006). De acordo com Lima (2005), a maioria das manifestações patológicas que ocorrem em uma edificação surgem após a ocupação pelos usuários, podendo ser afetadas pela má utilização dos sistemas ou falta de uma adequada manutenção, incluindo a realização de alterações em função de reformas sem o devido acompanhamento de um profissional qualificado. Para Richter (2007) e Figueiredo et al. (2017), as manifestações patológicas mais comuns encontradas nas edificações de alvenaria estrutural são umidades, fissuras e manchamento de fachadas, as quais são brevemente discutidas a seguir.

\section{Fissuras nas edificações de alvenaria estrutural}

Conforme Holanda Júnior (2002), as fissuras são manifestações patológicas comuns nas edificações de alvenaria estrutural, por serem essas construções rígidas, frágeis e com baixa resistência à tração. As fissuras também representam a manifestação patológica mais observada pelos leigos, pois, mesmo sem gravidade, causam preocupações aos usuários em relação à segurança e estabilidade da edificação (DUARTE, 1998). Consequentemente, as fissuras podem interferir na estética, na funcionalidade e até mesmo na durabilidade da edificação. Um exemplo disso são as fissuras causadas por retração ou comumente chamadas fissuras mapeadas, as quais se formam ângulo próximo de $90^{\circ}$ nos pontos onde há cruzamento entre elas. Segundo Segat (2006), as condições climáticas durante a execução de revestimentos em fachadas externas das edificações têm grande influência, uma vez que a aplicação do revestimento de argamassa em dias muito secos ou quentes pode provocar uma desidratação precoce da argamassa, ocasionando, algumas vezes, as fissuras mapeadas. Segundo Santos et al. (2017), se não há uma adequada recuperação ou reparação das fissuras, essas podem ocasionar o aparecimento de outros tipos de manifestações patológicas nas edificações, tais como umidade, manchamento, infiltrações e desplacamento de revestimentos.

\section{Umidade nas edificações}

A presença de umidade pode ocasionar uma má aparência tanto nas áreas internas como nas partes externas de uma edificação, além de gerar desconforto aos usuários. Se não for corrigida, a umidade pode resultar em 
degradação da edificação. Existem várias causas para o surgimento da umidade em um edifício, as quais podem estar associadas aos materiais e às técnicas construtivas, como também à idade da edificação e ao clima da região ou até mesmo à soma de todas essas causas (POYASTRO, 2011). Umas das causas mais comuns para o aparecimento de umidade em uma edificação, segundo Zucchetti (2016), é a ação conjunta do vento com a chuva. Segundo a NBR 15575-4 (ABNT, 2013), os sistemas de vedações verticais externas de uma edificação devem ser projetados de forma a serem estanques à água da chuva combinada à ação dos ventos, ou seja, não podem apresentar infiltrações que proporcionem escorrimentos, borrifamentos ou formação de gotas de água aderentes nas faces da fachada.

\section{Manchamento de fachadas}

Existem inúmeros agentes agressivos no ambiente que podem afetar os empreendimentos habitacionais e consequentemente, causar doenças e desconforto aos moradores dessas edificações (MELO JUNIOR, 2010). As fachadas são fundamentais para o isolamento dos usuários em relação ao ambiente externo e, consequentemente, para a habitabilidade das edificações, por oferecem estanqueidade, segurança estrutural, proteção térmica e acústica (RESENDE, 2004). De acordo com Petrucci (2000), o ciclo de vida das edificações está diretamente associado às condições atmosféricas da localização das edificações. Dependendo das características atmosféricas, as edificações podem sofrer desgastes e deterioração contínua, causando desde o manchamento e perda da estética da fachada, até o surgimento de manifestações patológicas mais graves. Segundo Poyastro (2011), uns dos agentes agressivos que podem influenciar o aparecimento do manchamento nas superfícies das fachadas das edificações são as partículas de poluição atmosférica combinadas à água da chuva e à ação dos ventos. Um exemplo de manchamento em fachadas são os denominados “fantasmas”, que podem ser causados por dois fatores: condensação ou absorção diferenciada de umidade na superfície do revestimento exterior das edificações. De acordo com Segat (2006), essa manifestação patológica pode surgir devido às diferenças de temperatura incidentes na face do revestimento no decorrer do período de secagem após uma chuva, uma vez que a base de aplicação do revestimento é heterogênea, ou seja, as juntas de assentamento e os componentes da alvenaria apresentam diferentes coeficientes de absorção de água, secando, assim, com velocidades diferentes.

\section{Método de pesquisa}

\section{Abordagem metodológica}

Este estudo adotou como abordagem metodológica Design Science Research, também conhecida como pesquisa construtiva, a qual visa a desenvolver conceitos de solução para classes de problemas do mundo real, por meio do projeto ou desenvolvimento de um artefato inovador (VAN AKEN, 2004). De acordo como Hevner et al. (2004), a criação de um artefato requer uma compreensão profunda do problema a ser resolvido, com a finalidade de desenvolver uma solução adequada. Esta compreensão pode levar à identificação de novos problemas, resultando em novas questões e soluções (HEVNER et al., 2004). As soluções propostas devem ser testadas com base em critérios de utilidade e aplicabilidade, considerando o contexto para o qual foram desenvolvidas (MARCH; SMITH, 1995). Segundo Dresch (2013), em Design Science Research, busca-se desenvolver soluções satisfatórias para uma gama de situações consideradas, não necessariamente ótimas ou universais.

O artefato proposto neste estudo é um método para avaliar a qualidade construtiva das áreas comuns de empreendimentos habitacionais no período de pós-ocupação, sob uma perspectiva técnica. Faz parte do método um instrumento de coleta de dados, que é aplicado a partir de inspeções visuais, as quais podem ser realizadas de forma rápida e simples. O instrumento foi desenvolvido para profissionais com formação em arquitetura e engenharia civil que atuem em empresas construtoras, assim como profissionais encarregados de realizar inspeções, fiscalizações ou auditorias da qualidade em empreendimentos habitacionais.

\section{Delineamento da pesquisa}

Na Figura 3 é apresentado o delineamento da pesquisa, a qual foi dividida em três etapas. Na etapa 1 foram identificados os requisitos de normas para áreas comuns de empreendimentos habitacionais. Para tal fim, foi necessária uma revisão bibliográfica, na qual foram analisados resultados de estudos anteriores sobre avaliação de empreendimentos habitacionais de interesse social, assim como as normas técnicas vigentes de desempenho (ABNT, 2013a) e acessibilidade (ABNT, 2015). Merece destaque o estudo de Berr (2016), que desenvolveu um método para a avaliação da qualidade de unidades de EHIS, com base na qualidade percebida pelos 
usuários e na confiabilidade do produto. Em seguida foram realizadas reuniões com representantes de diferentes organizações atuantes em EHIS: síndicos de EHIS, técnicos de órgãos públicos, especialistas e pesquisadores. Essas reuniões tiveram a finalidade de escolher as áreas comuns a serem a avaliadas. Também nesta etapa foi desenvolvida a primeira versão da solução, sendo os resultados de sua aplicação discutidos com especialistas acadêmicos e técnicos de órgãos públicos.

Figura 3 - Delineamento da pesquisa
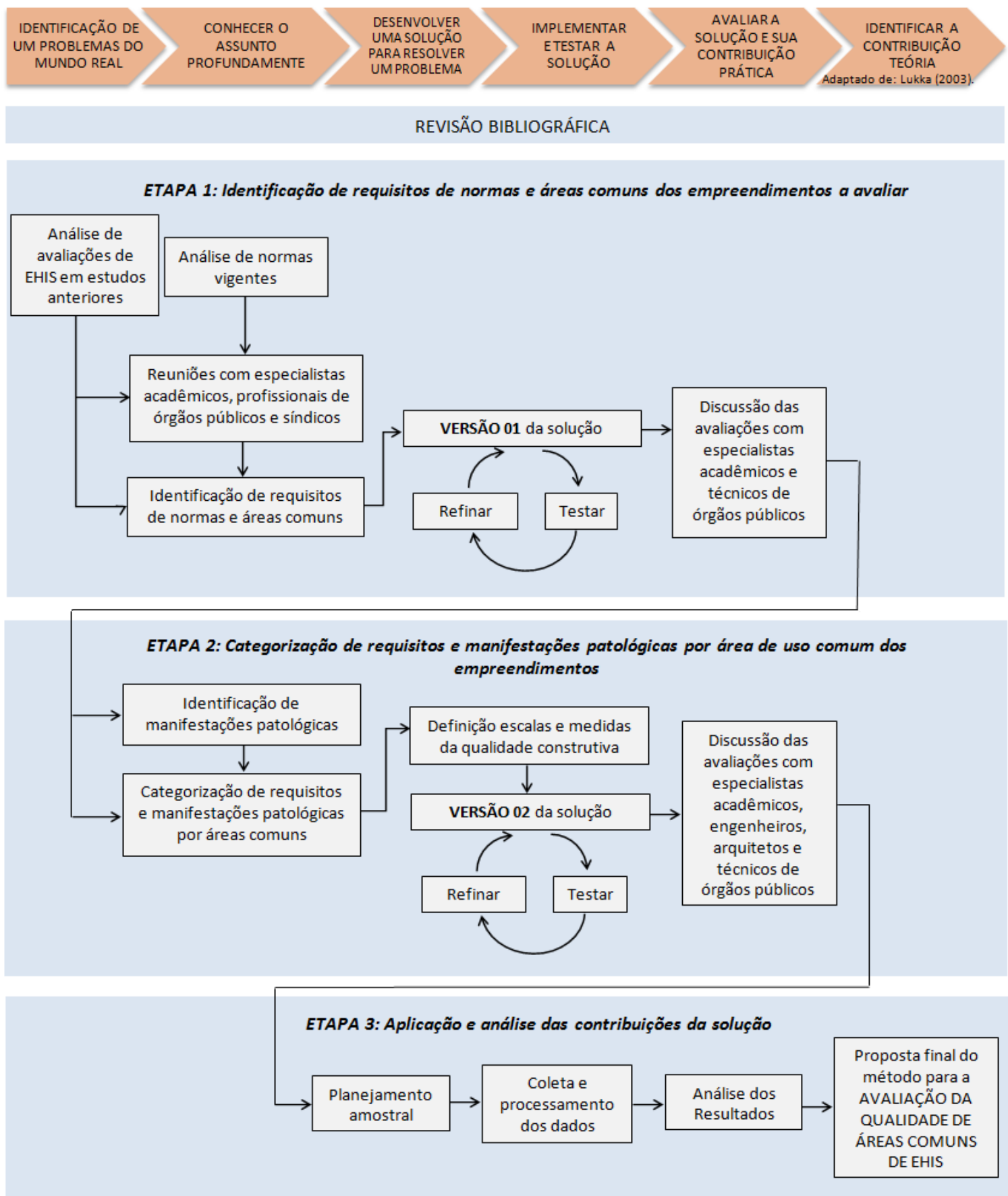
Na segunda etapa, foram identificados os requisitos relevantes das normas e os tipos de falhas ou manifestações patológicas principais, a serem consideradas na avaliação. Essa atividade foi denominada como “categorização de requisitos e manifestações patológicas por área de uso comum dos empreendimentos”. O objetivo dessa categorização foi organizar os itens com a finalidade de que, na coleta de dados, se possa detectar rapidamente as manifestações patológicas a serem analisadas, bem como o atendimento, ou não, dos requisitos nas diversas áreas comuns dos condomínios estudados. Também nessa etapa foram definidas as escalas e medidas para avaliar a qualidade pós-ocupação das áreas comuns. Ao final dessa etapa, foi desenvolvida uma segunda versão do método de avaliação, a qual também foi discutida com especialistas e técnicos de órgãos públicos.

Finalmente, na etapa 3 o método proposto foi aplicado integralmente e avaliado em relação à sua utilidade e facilidade de uso. A partir das reflexões sobre a avaliação final do artefato consolidou-se a proposta final do método.

\section{Escalas e medidas}

Para avaliar a qualidade pós-ocupação das áreas comuns dos EHIS, o instrumento de coleta de dados dispõe de duas escalas de medição. A primeira delas é denominada de escala de escolha simples, na qual o respondente tem três opções de resposta: sim, não e não se aplica (N/A). Esse tipo de medição foi utilizado para avaliar itens nos quais a questão é sobre o atendimento ou não de requisitos de normas nas áreas comuns.

A segunda escala de medida utilizada no instrumento de coleta foi baseada na técnica de FMEA (Failure Mode and Effect Analysis) ou Análise de Modo e Efeito de Falha. De acordo com Helman e Andery (1995), o princípio do FMEA é a prevenção de falhas, por meio da estimativa do risco, como produto da severidade do efeito, frequência de ocorrência e probabilidade de detecção. Essa técnica possibilita a análise das falhas no sistema estudado e suas respectivas causas, encontrando mecanismos para detectar a falha antes que o defeito ocorra (HELMAN; ANDERY, 1995). Essa escala de medida foi utilizada para avaliar o nível de falhas visíveis nas áreas comuns dos empreendimentos, ou seja, as manifestações patológicas identificadas nas áreas estudadas. Nesse sentido, foram utilizados dois índices na avaliação de cada manifestação patológica ou falha, baseados no estudo de Alexandre (2008):

(a) o índice de ocorrência da falha, que é uma estimativa da porcentagem de detecção da ocorrência da falha sobre o sistema estudado, obtida por meio de observação direta; e

(b) o índice de gravidade da falha que indica o nível de gravidade do efeito da falha sobre o sistema estudado.

Os dois índices têm uma escala de 1 a 10, como ilustrado na Figura 4. Se a manifestação patológica não é detectada (Não Detec*), não é necessário avaliar a gravidade da falha. Dessa forma, o indicador de impacto (Equação 1) é o produto de (i) e (ii). O indicador de impacto é uma medida de gravidade ponderado pela ocorrência da falha. Quanto maior o valor desse indicador, maior tende a ser o impacto detectado na falha observada.

Indicador de Impacto: $\operatorname{Impact}(i)=\sum_{I=1}^{K}\left(f_{i} * G r_{i}\right)$

Eq. 1

Onde:

$i=$ impacto para o sistema $i$

$K=$ número de sistemas avaliados;

$f_{i}=$ ocorrência da falha; e

$G r_{i}=$ gravidade da falha.

A partir do indicador de impacto, as manifestações podem ser priorizadas tanto para a recuperação de empreendimentos habitacionais de interesse social existentes, como na prevenção de problemas em construções futuras. No Quadro 1 são apresentados os critérios para a definição dos índices de ocorrência e gravidade da falha nas manifestações patológicas avaliadas com os quais se determina o indicador de impacto mencionado anteriormente.

Para entender melhor o critério para a definição do índice de ocorrência da falha no sistema estudado, apresenta-se na Figura 5 um exemplo da estimativa da porcentagem de detecção da ocorrência de falha na manifestação patológica “fissuras em cantos das esquadrias a $45^{\circ}$ ” na fachada de uma edificação. 
Figura 4 - Escalas de ocorrência e gravidade da falha

\begin{tabular}{|c|c|c|c|}
\hline N/A & \multicolumn{2}{|r|}{ OCORRÊNCIA DA FALHA } & GRAVIDADE DA FALHA \\
\hline & Não Detec * & BAIXA MODERADA ALtA MUITO ALtA & BAIXA MODERADA ALtA MüITO ALTA \\
\hline & & $\begin{array}{lllll}1 & 2 & 3 & 4 & 5\end{array}$ & 45 \\
\hline
\end{tabular}

Quadro 1 - Critérios para definição dos índices de ocorrência e gravidade de falha

\begin{tabular}{|c|c|c|c|}
\hline \multicolumn{2}{|c|}{ Índice de Ocorrência da Falha } & \multicolumn{2}{c|}{ Índice de Gravidade da Falha } \\
\hline $\left.\begin{array}{c}\text { Escala de medida } \\
\text { (Não Detectada }\end{array}\right)$ & $\begin{array}{c}\text { Falha não detectada: 0\% de detecção } \\
\text { da ocorrência da falha no sistema } \\
\text { estudado }\end{array}$ & Escala de medida & Critério \\
\hline $\begin{array}{c}\text { Baixa } \\
(1 \text { a 3,9) }\end{array}$ & $\begin{array}{c}\text { Ocorre poucas vezes: } 1 \% \text { a } 25 \% \text { de } \\
\text { detecção da ocorrência da falha no } \\
\text { sistema estudado }\end{array}$ & $\begin{array}{c}\text { Baixa } \\
(1 \text { a 3,9) }\end{array}$ & $\begin{array}{c}\text { Quase não é } \\
\text { percebida a falha }\end{array}$ \\
\hline $\begin{array}{c}\text { Moderada } \\
(4 \text { a } 6)\end{array}$ & $\begin{array}{c}\text { Ocorre algumas vezes: } 26 \% \text { a } 50 \% \\
\text { de detecção da ocorrência da falha } \\
\text { no sistema estudado }\end{array}$ & $\begin{array}{c}\text { Moderada } \\
(4 \text { a 6) }\end{array}$ & $\begin{array}{c}\text { Ligeira deterioração } \\
\text { do sistema estudado }\end{array}$ \\
\hline $\begin{array}{c}\text { Alta } \\
(6,1 \text { a } 8,9)\end{array}$ & $\begin{array}{c}\text { Ocorre frequente: } 51 \% \text { a } 90 \% \text { de } \\
\text { detecção da ocorrência da falha no } \\
\text { sistema estudado }\end{array}$ & $\begin{array}{c}\text { Deterioração } \\
\text { significativa do } \\
\text { sistema estudado }\end{array}$ \\
\hline $\begin{array}{c}\text { Muito Alta } \\
(9 \text { a 10) }\end{array}$ & $\begin{array}{c}\text { Ocorre com muita frequência: } 91 \% \text { a } \\
100 \% \text { de detecção da ocorrência da } \\
\text { falha no sistema estudado }\end{array}$ & $\begin{array}{c}\text { Muito Alta } \\
\text { (9 a 10) }\end{array}$ & $\begin{array}{c}\text { O sistema estudado } \\
\text { deixa de funcionar e } \\
\text { afeta a segurança }\end{array}$ \\
\hline
\end{tabular}

Fonte: baseado em Helman e Andery (1995).

Figura 5 - Porcentagem de detecção da ocorrência da falha na manifestação patológica "fissuras em cantos das esquadrias a 45” em uma fachada de uma edificação

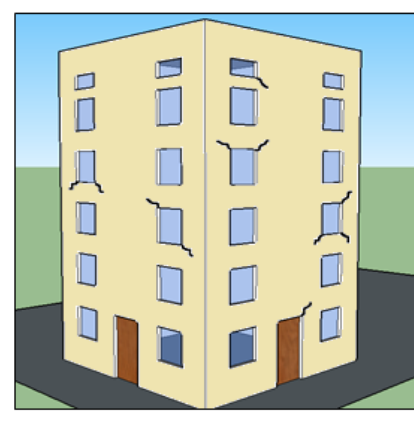

BAIXA - $1 \%$ a $25 \%$ de detecção da ocorrência da falha

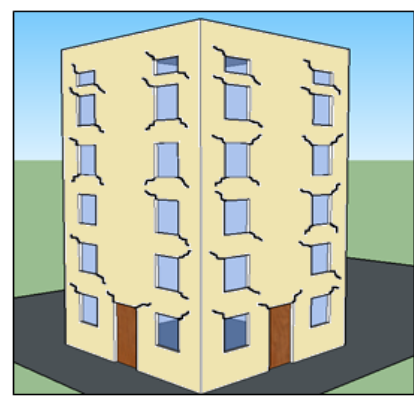

ALTA - $51 \%$ a $90 \%$

de detecção da ocorrência da falha

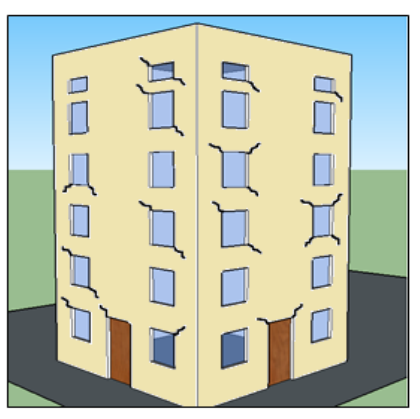

MODERADA $-26 \%$ a $50 \%$ de detecção da ocorrência da falha

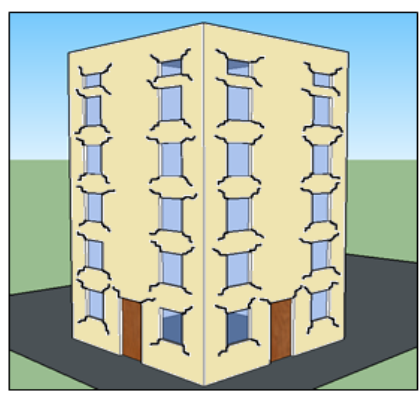

MUITO ALTA - $91 \%$ a $100 \%$ de detecção da ocorrência da falha 


\section{Planejamento amostral}

Para a seleção da amostra levaram-se em conta três critérios. O primeiro critério foi que os empreendimentos a serem avaliados tivessem sido executados em alvenaria estrutural, tipologia construtiva de prédios de 5 pavimentos e revestimento de argamassa nas fachadas, por ser um sistema amplamente utilizado na construção dos EHIS no Rio Grande do Sul. Além disso, ao escolher um único sistema construtivo, foi possível homogeneizar a amostra, facilitando a análise do surgimento de falhas ou manifestações patológicas. O segundo critério foi que os EHIS deveriam possuir mais de um ano de ocupação, uma vez que, após esse tempo, tendem a surgir mais manifestações patológicas. O terceiro e último critério para a seleção da amostra foi a faixa de renda dos empreendimentos do Programa Minha Casa, Minha Vida (PMCMV). Neste estudo as faixas de renda avaliadas foram as faixas I e II, considerando que o número de empreendimentos para faixa de renda III é pequeno em comparação às demais. Na Figura 6 apresentam-se, por região, os empreendimentos habitacionais de interesse social selecionados para o estudo.

No total foram avaliados 10 empreendimentos e 96 blocos (prédios) entre os 104 da amostra, como é apresentado no Quadro 2.

Figura 6 - Empreendimentos selecionados na Região Metropolitana de Porto Alegre, RS

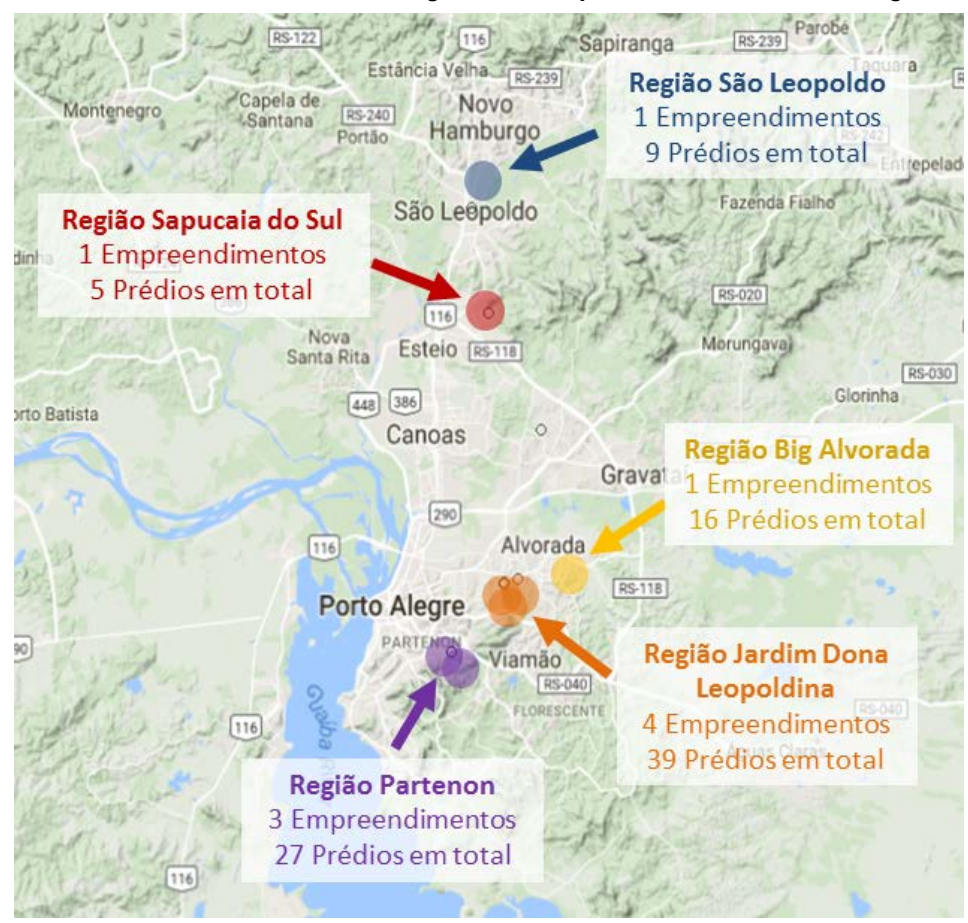

Fonte: adaptada de Google Maps (2018).

Quadro 2 - População do estudo

\begin{tabular}{|c|c|c|c|c|c|c|}
\hline $\begin{array}{c}\text { Empreendi- } \\
\text { mento }\end{array}$ & Cidade & Construtora & $\begin{array}{c}\text { Faixa } \\
\text { de } \\
\text { renda }\end{array}$ & $\begin{array}{c}\mathbf{N}^{\mathbf{o}} \text { prédios } \\
\text { existentes } \\
\left(\boldsymbol{N}_{\text {blocos }}\right)\end{array}$ & $\begin{array}{c}\mathbf{N}^{\mathbf{0}} \text { prédios } \\
\text { avaliados } \\
\left(\boldsymbol{n}_{\text {blocos }}\right)\end{array}$ & $\begin{array}{c}\text { Idade } \\
\text { (em } \\
\text { anos) }\end{array}$ \\
\hline A & Porto Alegre & L & 1 & 10 & 10 & 1 \\
\hline B & Porto Alegre & L & 1 & 9 & 9 & 1 \\
\hline C & Sapucaia do Sul & M & 2 & 5 & 5 & 6 \\
\hline D & São Leopoldo & N & 1 & 9 & 9 & 4 \\
\hline E & Porto Alegre & O & 2 & 8 & 8 & 4 \\
\hline F & Porto Alegre & O & 2 & 11 & 8 & 5 \\
\hline G & Porto Alegre & O & 2 & 13 & 12 & 3 \\
\hline H & Porto Alegre & N & 2 & 20 & 16 & 7 \\
\hline I & Porto Alegre & L & 1 & 8 & 8 & 2 \\
\hline J & Porto Alegre & O & 2 & 11 & 11 & 6 \\
\hline
\end{tabular}


Para cada empreendimento avaliado, foi adotado o cálculo de tamanho de amostra aleatória simples nos blocos. Foi adotado um erro amostral de $10 \%$ e um nível de confiança de $95 \%$. A proporção utilizada para dimensionar a amostra da quantidade de blocos a serem avaliados foi de $50 \%$, tendo em vista o fato de que as informações prévias sobre a qualidade das áreas comuns de EHIS ainda eram escassas.

\section{Resultados}

Inicialmente, descreve-se o método proposto, na sua versão final. Após, são apresentadas as análises da aplicação deste, incluindo a coleta, processamento e análise dos dados na amostra dos empreendimentos estudados. As análises apresentadas correspondem a resultados descritivos sobre o atendimento ou não de requisitos de norma sobre acessibilidade nos empreendimentos habitacionais. Também foi feita uma análise entre a porcentagem de deteç̧ão de manifestações patológicas nos prédios avaliados e as médias do indicador de impacto das mesmas manifestações patológicas. Ao final, são mostrados os resultados de uma análise comparativa entre os empreendimentos de acordo com sua idade de construção e a construtora responsável pela execução, com relação ao indicador de impacto das manifestações patológicas encontradas na avaliação. Conforme mencionado no item sobre escalas e medidas, o indicador de impacto é o resultado da multiplicação dos índices de ocorrência e de gravidade de falha.

\section{Método proposto}

A Figura 7 apresenta uma visão geral do método proposto para a avaliação técnica da qualidade nas áreas comuns. O método está estruturado em quatro etapas. A primeira etapa corresponde à construção e refinamento do instrumento de coleta de dados. São reunidas informações referentes ao não atendimento de requisitos de normas e à ocorrência de manifestações patológicas nos empreendimentos a avaliar. Esses dados podem ser obtidos por meio de reclamações de usuários, histórico de inspeções técnicas ou resultados de estudos anteriores. Após a coleta destas informações, pode-se identificar e caracterizar todos estes dados por área de uso comum nos empreendimentos.

A etapa 2 do método refere-se à definição do plano amostral para a avaliação e também à definição de escalas e medidas a serem adotadas para a avaliação da qualidade das áreas comuns. A terceira etapa corresponde à coleta e ao processamento dos dados. No processamento são aplicadas técnicas estatísticas para análise dos dados coletados. A quarta e última etapa refere-se à análise dos resultados dos itens avaliados.

\section{Manifestações patológicas e requisitos de norma a avaliar}

Foram estabelecidos para cada área comum os requisitos de norma e as manifestações patológicas a serem consideradas. Os requisitos de norma identificados no método, foram extraídos das normas técnicas vigentes, os de desempenho da NBR 15575 (ABNT, 2013a) e de acessibilidade da NBR 9050 (ABNT, 2015). Já as manifestações patológicas foram baseadas em estudos anteriores, como os de Richter (2007) e de Figueiredo et al. (2017). Essa categorização foi feita com o intuito de que os avaliadores possam fazer uma avaliação em relação aos requisitos e às manifestações patológicas no momento da coleta de dados. No Quadro 3 apresentase de forma geral a categorização de requisitos de norma e as manifestações patológicas por área de uso comum, o tipo de escala de medição que foi utilizado para a avaliação e a origem do requisito ou falha avaliada.

\section{Instrumento de coleta de dados}

O instrumento de coleta desenvolvido para este método está dividido em três partes principais:

(a) informações gerais do empreendimento;

(b) avaliação das áreas comuns do condomínio; e

(c) avaliação das áreas comuns dos prédios ou blocos.

Adotou-se como princípio que todas as partes do instrumento de coleta podem ser preenchidas com base em inspeções visuais das áreas comuns, de forma a tornar a avaliação mais expedita.

Na primeira parte do questionário, as informações coletadas são sobre a localização do empreendimento, horário e dia da coleta, condições atmosféricas no momento da coleta, nome do síndico e dados gerais do condomínio, tais como frequência de manutenção de fachadas, pisos e coberturas. Na segunda parte do instrumento de coleta, os itens a serem avaliados fazem parte das áreas comuns do condomínio, tais como calçadas e estacionamentos, sem considerar a parte interna dos prédios. A última parte do questionário trata 
da avaliação dos prédios ou blocos do condomínio, tanto na parte externa como interna deles. A parte externa refere-se às fachadas (Figura 8), e a interna, à circulação interna dos prédios.

\section{Figura 7 - Método de avaliação técnica da qualidade em áreas comuns de EHIS}

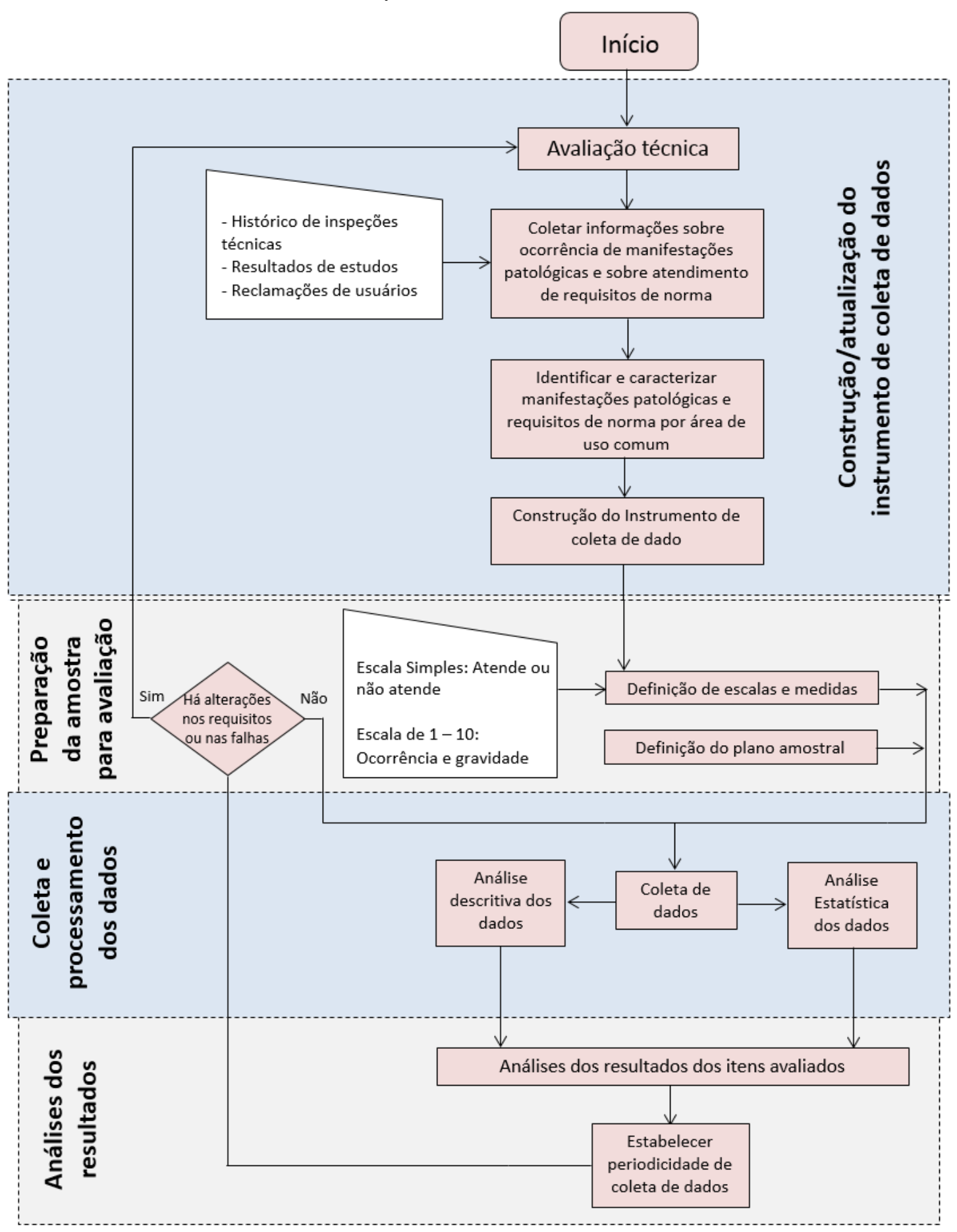


Quadro 3 - Categorização de requisitos e manifestações patológicas por área de uso comum

\begin{tabular}{|c|c|c|c|}
\hline $\begin{array}{l}\text { Área Comum a } \\
\text { Avaliar }\end{array}$ & $\begin{array}{l}\text { Requisito / Manifestação } \\
\text { Patológica a Avaliar }\end{array}$ & $\begin{array}{l}\text { Escala de Medição } \\
\text { para Avaliação }\end{array}$ & $\begin{array}{l}\text { Proveniência do } \\
\text { Requisito / Falha }\end{array}$ \\
\hline \multirow{5}{*}{$\begin{array}{l}\text { CALÇADAS E } \\
\text { ESTACIONA- } \\
\text { MENTO }\end{array}$} & $\begin{array}{l}\text { As calçadas dispõem de } \\
\text { superfície regular firme e estável }\end{array}$ & Simples & $\begin{array}{l}\text { NBR } 9050 \text { (ABNT, } \\
\text { 2015) / NBR 15575-3 } \\
\text { (ABNT, 2013b) }\end{array}$ \\
\hline & $\begin{array}{c}\text { As calçadas estão livres de } \\
\text { obstáculos }\end{array}$ & Simples & $\begin{array}{l}\text { NBR } 9050 \text { (ABNT, } \\
\text { 2015) }\end{array}$ \\
\hline & $\begin{array}{c}\text { O estacionamento dispõe vagas } \\
\text { demarcadas para pessoas } \\
\text { portadoras de deficiência } \\
\end{array}$ & Simples & $\begin{array}{l}\text { NBR } 9050 \text { (ABNT, } \\
\text { 2015) }\end{array}$ \\
\hline & $\begin{array}{c}\text { As calçadas dispõem de } \\
\text { sinalização tátil e visual no piso }\end{array}$ & Simples & $\begin{array}{l}\text { NBR } 9050 \text { (ABNT, } \\
\text { 2015) }\end{array}$ \\
\hline & $\begin{array}{l}\text { Desgaste superficial nas peças de } \\
\text { sinalização tátil e visual no piso }\end{array}$ & Ocorrência e Gravidade & Entrevista \\
\hline \multirow{14}{*}{ FACHADAS } & $\begin{array}{l}\text { Fissuras em cantos das esquadrias } \\
\text { a } 45^{\circ}\end{array}$ & Ocorrência e Gravidade & Estudos anteriores \\
\hline & $\begin{array}{l}\text { Fissuras no entorno das } \\
\text { esquadrias }\end{array}$ & Ocorrência e Gravidade & $\begin{array}{l}\text { NBR 15575-4 (ABNT, } \\
\text { 2013c)/ Estudos } \\
\text { anteriores }\end{array}$ \\
\hline & Fissuras mapeadas & Ocorrência e Gravidade & $\begin{array}{l}\text { NBR 15575-4 (ABNT, } \\
\text { 2013c)/ Estudos } \\
\text { anteriores }\end{array}$ \\
\hline & $\begin{array}{l}\text { Fissuras horizontais abaixo da } \\
\text { laje do último pavimento }\end{array}$ & Ocorrência e Gravidade & $\begin{array}{l}\text { NBR 15575-4 (ABNT, } \\
\text { 2013c)/ Estudos } \\
\text { anteriores }\end{array}$ \\
\hline & $\begin{array}{c}\text { Fissuras horizontais próxima do } \\
\text { piso (térreo) }\end{array}$ & Ocorrência e Gravidade & $\begin{array}{l}\text { NBR 15575-4 (ABNT, } \\
\text { 2013c)/ Estudos } \\
\text { anteriores }\end{array}$ \\
\hline & $\begin{array}{c}\text { Descolamento/desplacamento de } \\
\text { revestimento de argamassa / } \\
\text { cerâmica }\end{array}$ & Ocorrência e Gravidade & $\begin{array}{l}\text { NBR 15575-4 (ABNT, } \\
\text { 2013c) }\end{array}$ \\
\hline & $\begin{array}{c}\text { Descascando/desagregamento da } \\
\text { pintura } \\
\end{array}$ & Ocorrência e Gravidade & $\begin{array}{l}\text { NBR 15575-4 (ABNT, } \\
\text { 2013c) }\end{array}$ \\
\hline & Umidade ascensional no térreo & Ocorrência e Gravidade & Estudos anteriores \\
\hline & Umidade de Infiltração & Ocorrência e Gravidade & NBR 15575-4 \\
\hline & Fantasmas & Ocorrência e Gravidade & Estudos anteriores \\
\hline & Sujidade topo dos prédios & Ocorrência e Gravidade & Estudos anteriores \\
\hline & Sujidade abaixo das janelas & Ocorrência e Gravidade & ABNT NBR 15575-4 \\
\hline & $\begin{array}{l}\text { Deterioração ou danificação do } \\
\text { peitoril das janelas }\end{array}$ & Ocorrência e Gravidade & Estudos anteriores \\
\hline & $\begin{array}{c}\text { Sujidade pela improvisação de } \\
\text { instalações de equipamentos }\end{array}$ & Ocorrência e Gravidade & Estudos anteriores \\
\hline \multirow{5}{*}{$\begin{array}{l}\text { CIRCULAÇÃO } \\
\text { INTERNA DOS } \\
\text { PRÉDIOS }\end{array}$} & $\begin{array}{l}\text { A superfície do piso é acessível } \\
\text { sem desníveis abruptos }\end{array}$ & Simples & $\begin{array}{l}\text { NBR 9050 (ABNT, } \\
\text { 2015)/ NBR 15575-3 } \\
(\mathrm{ABNT}, 2013 \mathrm{~b})\end{array}$ \\
\hline & $\begin{array}{c}\text { Ocorrência de fissuras, bolhas } \\
\text { e/ou áreas descascando nas } \\
\text { paredes internas } \\
\end{array}$ & Ocorrência e Gravidade & $\begin{array}{l}\text { NBR 15575-4 (ABNT, } \\
\text { 2013c) }\end{array}$ \\
\hline & $\begin{array}{l}\text { Umidade ascensional nas paredes } \\
\text { internas do térreo }\end{array}$ & Ocorrência e Gravidade & Estudos anteriores \\
\hline & $\begin{array}{c}\text { Infiltrações que proporcionem } \\
\text { manchas de escorrimentos ou de } \\
\text { umidade nas janelas das paredes } \\
\text { internas } \\
\end{array}$ & Ocorrência e Gravidade & $\begin{array}{l}\text { NBR 15575-4 (ABNT, } \\
\text { 2013c) }\end{array}$ \\
\hline & $\begin{array}{l}\text { Manchas nas paredes e/ou na laje } \\
\text { (teto) devido à vazamentos da } \\
\text { coberta }\end{array}$ & Ocorrência e Gravidade & $\begin{array}{l}\text { NBR 15575-5 (ABNT, } \\
\text { 2013d) }\end{array}$ \\
\hline
\end{tabular}


Figura 8 - Instrumento de Coleta, Parte 3 - Fachadas

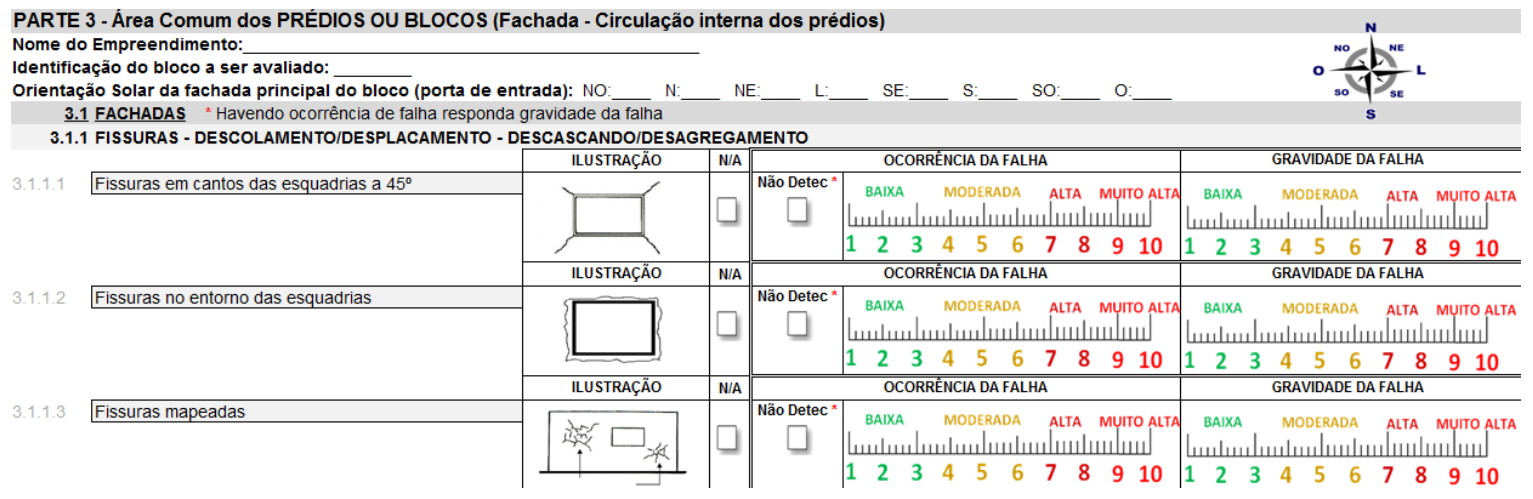

Para analisar as três partes do instrumento de coleta, em relação ao atendimento ou não de requisitos de norma mediante a escala simples de avaliação, foi feita uma análise descritiva dos resultados. Para analisar as manifestações patológicas, são consideradas as médias de impacto de cada manifestação, que é a média aritmética de todos os resultados da multiplicação dos índices de "ocorrência da falha" e de "gravidade da falha” de cada manifestação patológica analisada conforme explicado no capítulo de escalas e medidas. Para essa análise, fez-se uma comparação estatística mediante o teste global da ANOVA e Kruskal-Wallis (KW), com uma significância de 5\%, ajustada à distribuição Gama ou Normal entre subgrupos, com relação à média de impacto de cada manifestação patológica (quanto maior for a média do indicador de impacto maior tende a ser o impacto detectado na falha avaliada). Esta comparação foi feita entre subgrupos de acordo com a idade de uso de cada empreendimento avaliado e a construtora responsável pela execução da obra.

\section{Análise descritiva dos dados coletados}

Inicialmente foi feita uma análise descritiva dos resultados. Essa análise foi feita para os itens que tinham uma escala de avaliação simples, incluindo as questões sobre o atendimento ou não de requisitos de norma de acessibilidade dos usuários. A Figura 9 apresenta os resultados sobre a frequência da manutenção de diferentes sistemas do condomínio (tais como pisos, fachadas, coberturas e drenagem), a partir de informações fornecidas pelo síndico.

A Figura 9 indica que a maioria dos condomínios não faziam manutenção nos sistemas de pisos, fachadas e drenagem. Só no sistema de cobertura, observou-se que quase a metade dos empreendimentos já havia feito alguma atividade de manutenção. Porém, os síndicos afirmaram que foram feitos reparos, não propriamente para manutenções preventivas, e sim devido à infiltrações nos apartamentos dos últimos andares. Outro resultado que se destaca é que $80 \%$ das fachadas nunca recebeu manutenção, provavelmente porque a maioria dos empreendimentos era relativamente nova, com menos de 7 anos de uso.

A Figura 10 apresenta os resultados da análise descritiva da acessibilidade das calçadas e dos estacionamentos nos condomínios avaliados.

Dos quatro requisitos apresentados na Figura 10, destaca-se o não atendimento ao requisito da sinalização tátil e visual nas calçadas dos condomínios, especificado na Norma NBR 9050 (ABNT, 2015). Apesar de esse requisito existir há cerca de 15 anos, o mesmo não é atendido na amostra de empreendimentos do Programa Minha Casa, Minha Vida. Em 80\% das calçadas há uma interseção que dá acesso ao rebaixamento para a faixa de segurança de pedestre na rua. Entretanto, as observações diretas nos empreendimentos indicaram que esses rebaixamentos não estão sinalizados com piso tátil e visual de forma direcional e de alerta, como a Norma NBR 9050 (ABNT, 2015) estabelece, conforme indicado na revisão bibliográfica. Esse resultado aponta para o não atendimento ao livre deslocamento (estabelecido pela norma de acessibilidade), com segurança e autonomia para as pessoas com deficiência visual ou baixa visão. Na Figura 11 são apresentadas algumas das calçadas dos condomínios avaliados, nas quais a sinalização tátil e visual não foi atendida. A Figura 11 ilustra problemas de sinalização relativos à direção do deslocamento das pessoas, ao rebaixamento das calçadas, e à existência de barreiras (arquitetônicas, urbanísticas ou ambientais,) como, por exemplo, a parada de ônibus. Esse resultado coincide com o estudo de Zanini (2017), no qual este requisito também não era atendido. 
Figura 9 - Manutenção dos sistemas dos condomínios

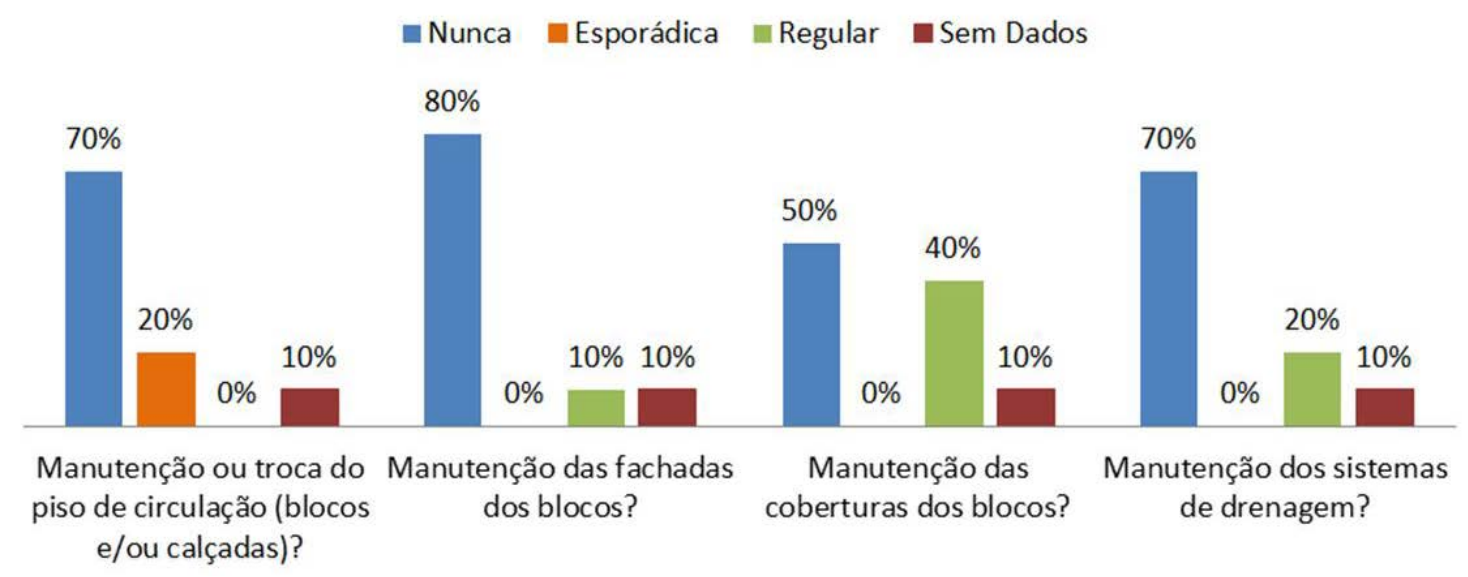

Figura 10 - Acessibilidade nas calçadas e nos estacionamentos dos condomínios

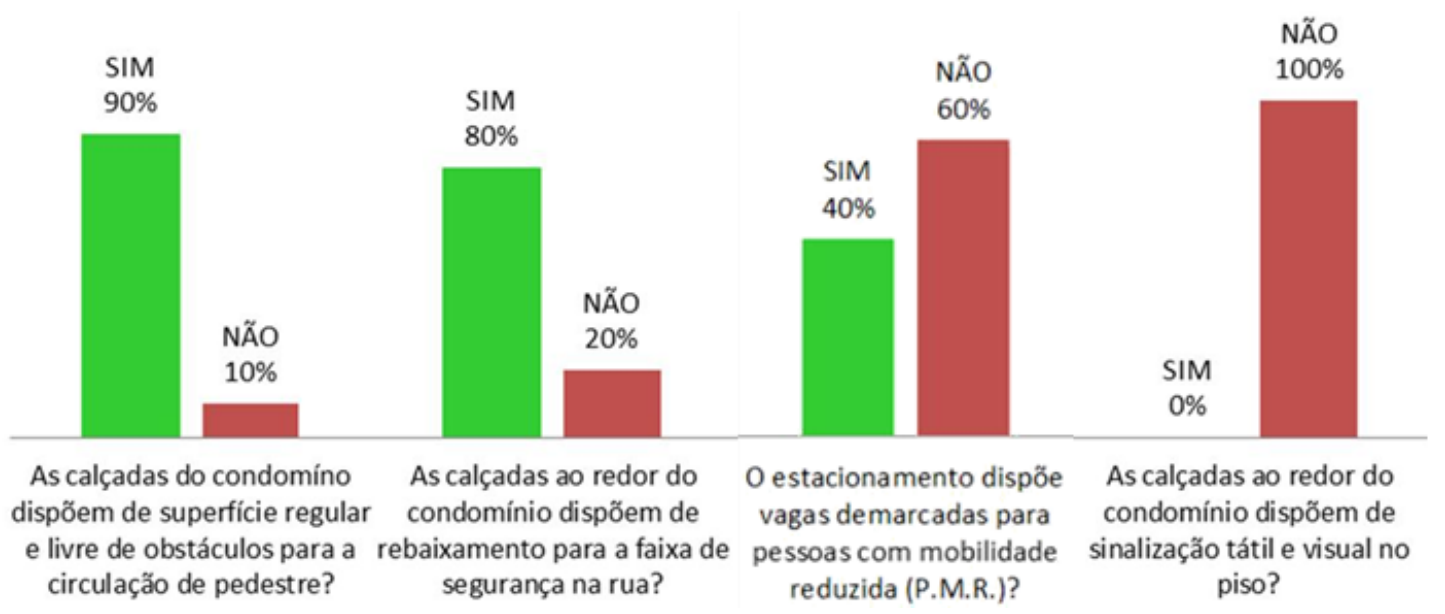

Figura 11 - Calçadas ao redor dos condomínios sem sinalização tátil e visual no piso

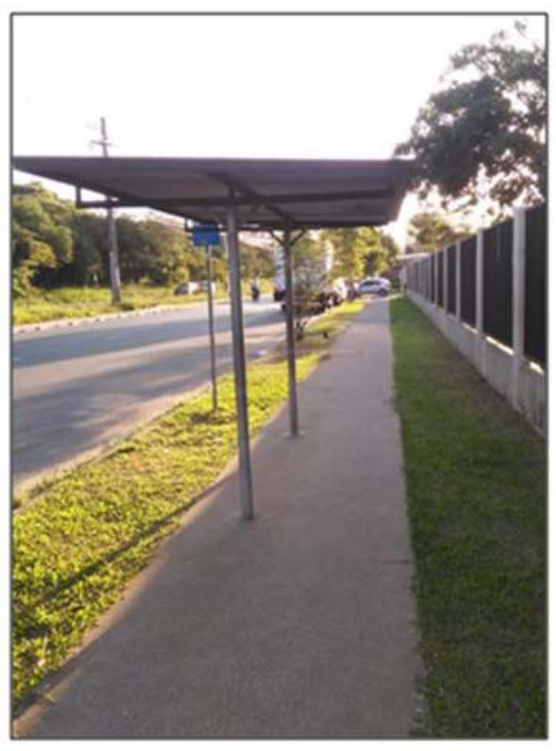

Calçada ao redor dos empreendimentos "F e J"

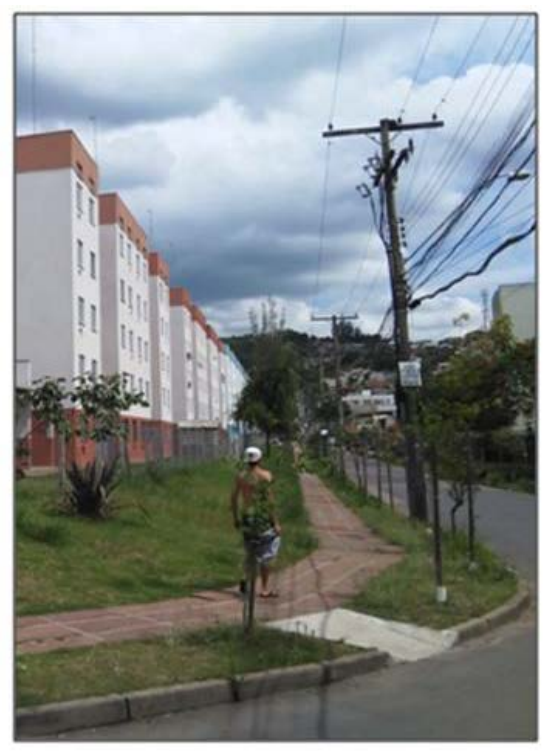

Calçada ao redor dos empreendimentos " $\mathrm{A}, \mathrm{B}$ e I" 
Outra análise descritiva feita no estudo foi a detecção das manifestações patológicas nos prédios avaliados e a análise do impacto delas. Em relação às áreas de circulação interna dos edifícios a manifestação patológica "Manchas nas paredes ou na laje (teto) devido a vazamentos da cobertura" foi detectada em menos da metade dos blocos avaliados, mas foi a manifestação com maior média de impacto como mostra a Figura 12. Por sua vez, a manifestação patológica "Desgaste superficial ou alteração de tonalidade do piso, visível a olho nu” foi detectada em mais da metade dos prédios (62\%), entretanto, a média de impacto foi a terceira menor de todas as manifestações patológicas, mostrando que esta falha apesar de ser observada na maior parte dos prédios, simultaneamente, não apresenta qualquer ameaça para a segurança do uso dos blocos de edifícios (Figura 13).

No que se refere às fachadas, as três manifestações patológicas com maiores médias de impacto encontradas nos prédios foram: "Fissuras mapeadas", "Fissuras no entorno das esquadrias" e "Fantasmas". Dessas três, duas, "Fissuras mapeadas" e "Fantasmas", foram detectadas em mais da metade dos blocos avaliados, como mostra a Figura 14. Já a falha "Fissuras no entorno das esquadrias", apesar de ser a segunda maior média de impacto entre todas as manifestações, foi também a manifestação menos detectada entre as manifestações patológicas avaliadas. Assim, apesar desta falha não ser frequente, pode ser considerada como de alto impacto, pela sua gravidade, como mostra a Figura 15. A gravidade é atribuída por que o surgimento dessas fissuras pode ocasionar o aparecimento de outras manifestações patológicas, como, por exemplo, infiltrações, umidades, descolamento e desplacamento de revestimentos de argamassa.

\section{Figura 12 - Resultados de porcentagem de detecção e médias de impacto de manifestações patológicas nas circulações internas dos prédios avaliados}

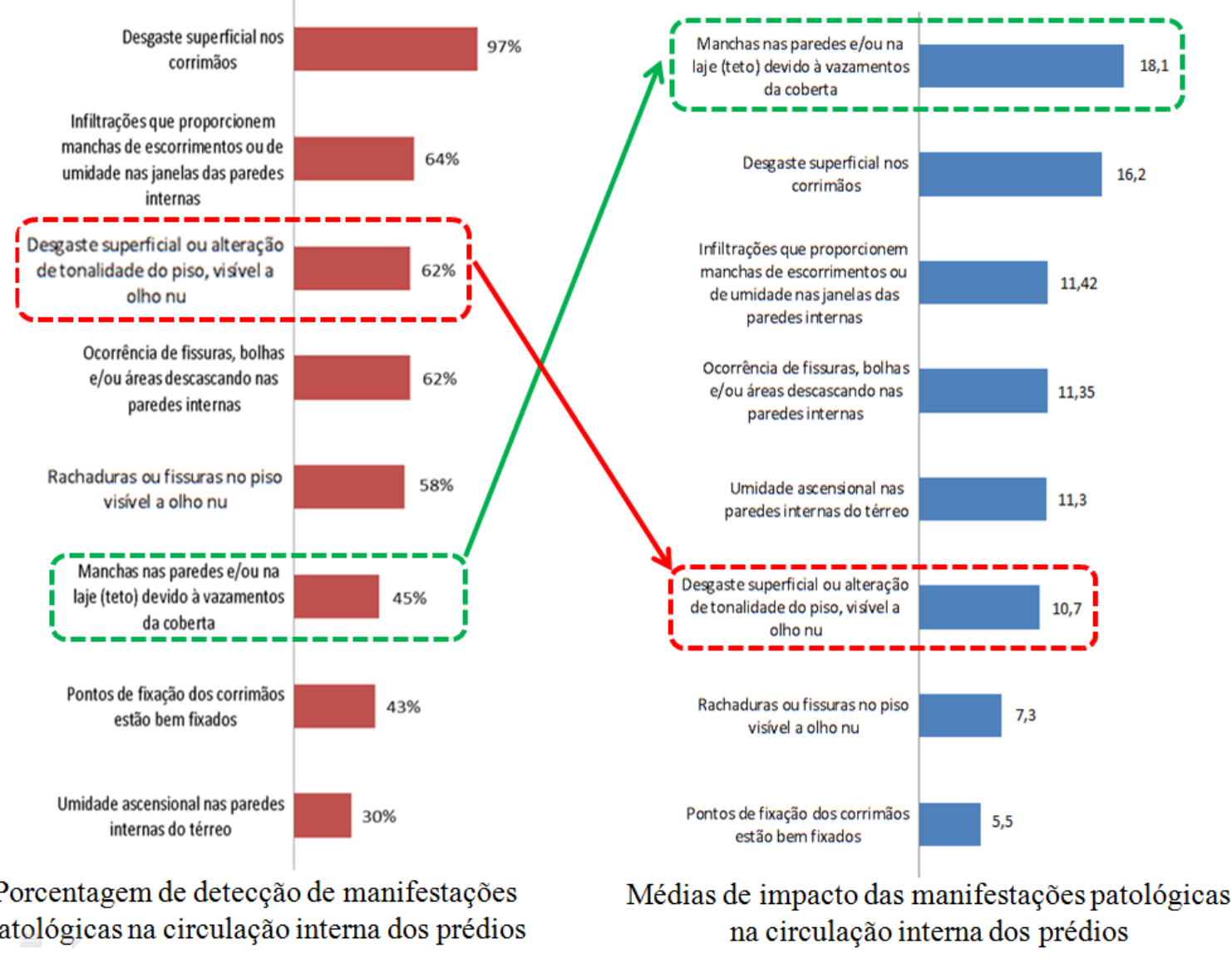


Figura 13 - Desgaste superficial ou alteração de tonalidade do piso, visível a olho nu

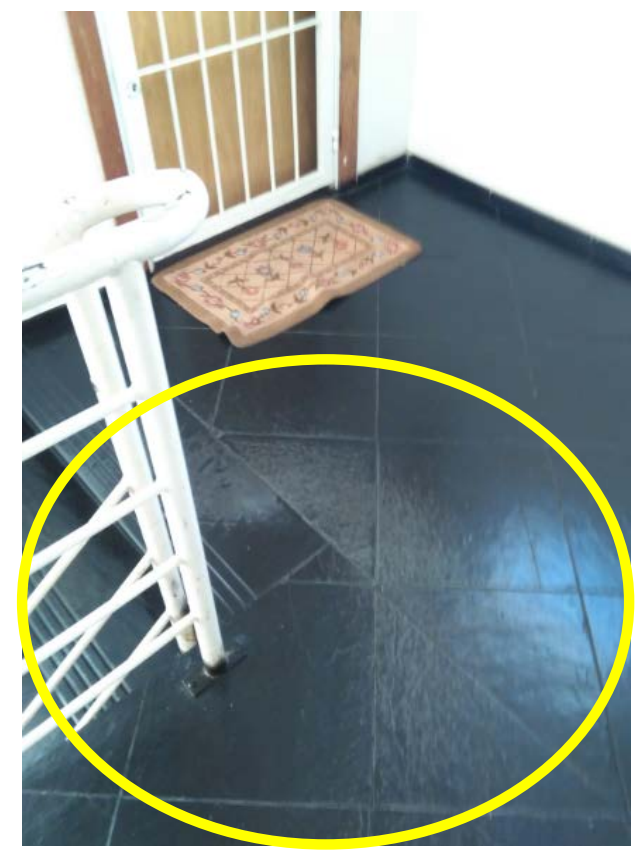

Figura 14 - Resultados de porcentagem de detecção e médias de impacto de manifestações patológicas em fachadas de empreendimentos avaliados

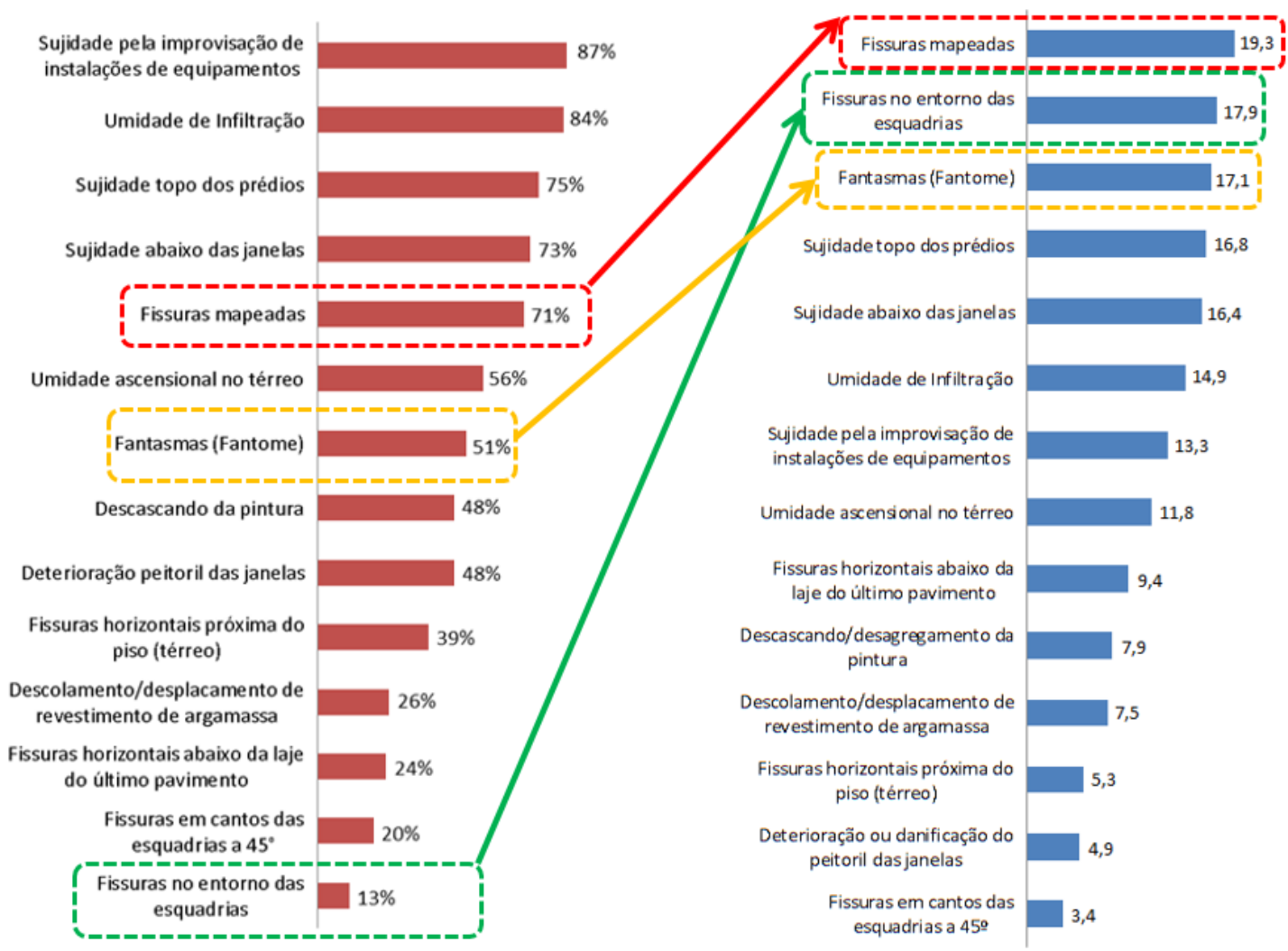

Porcentagem de detecção de manifestações patológicas nas fachadas
Médias de impacto das manifestações patológicas nas fachadas 
Figura 15 - Fissuras no entorno das esquadrias
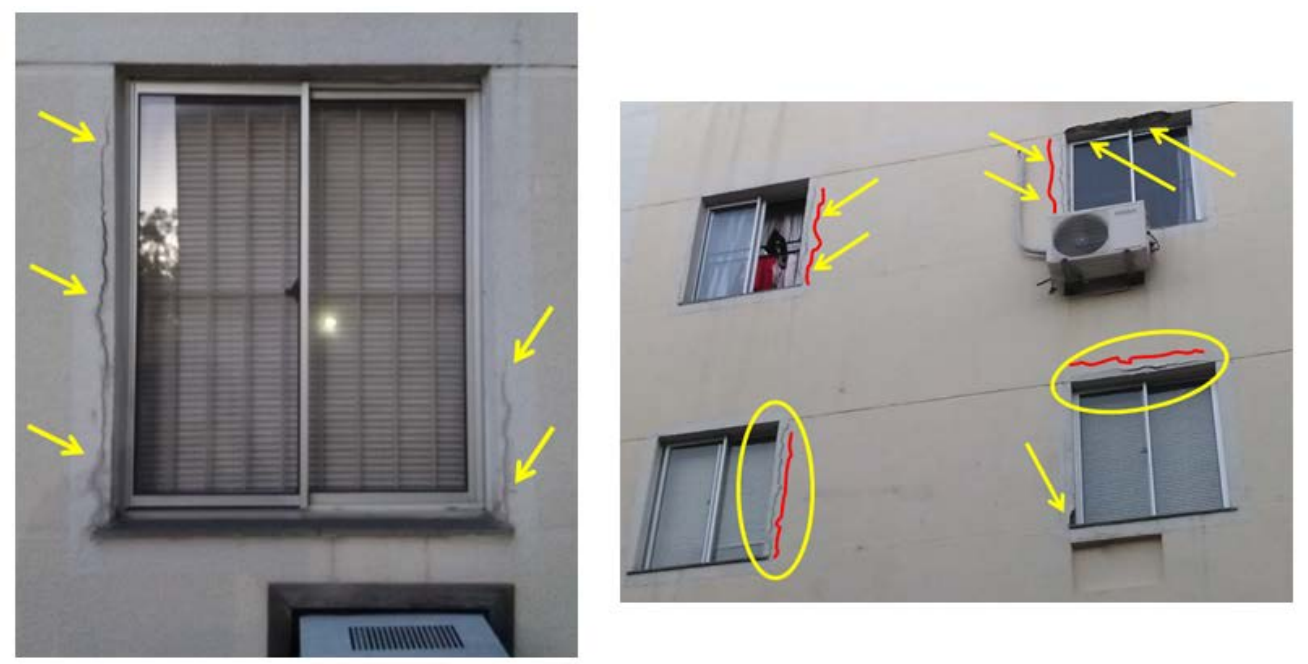

\section{Análise comparativa entre subgrupos com relação à média do indicador de impacto}

Para fazer uma análise comparativa entre subgrupos com relação à média do indicador de impacto das manifestações patológicas, têm-se os índices de "ocorrência da falha” e "gravidade da falha”, mencionados anteriormente. Foram inicialmente criados dois grandes grupos. O primeiro deles é o grupo relacionado à idade de uso de cada empreendimento avaliado, o qual foi dividido em três subgrupos:

(a) menos de 4 anos de uso;

(b) de 4 a menos de 6 anos de uso; e

(c) com 6 anos ou mais de uso.

O segundo grupo corresponde à construtora responsável pela execução da obra, o qual foi dividido em 4 subgrupos identificados por siglas (para manutenção do sigilo das empresas, foram omitidos os verdadeiros nomes). Como o objetivo desta análise é comparar as médias de impacto (média aritmética dos resultados do produto entre o índice de ocorrência da falha e o índice de gravidade da falha de cada manifestação avaliada) dos itens avaliados de cada subgrupo criado, foi necessário encontrar diferenças significativas entre as médias de impacto das manifestações patológicas. Para tal, foi realizado o teste global da ANOVA e Kruskal-Wallis (KW) em cada grupo, com uma significância de 5\%, ajustada à distribuição Gama ou Normal. Os resultados mostrados nos Quadros 4 e 5 referem-se às médias do indicador de impacto dos itens em que foram avaliadas a ocorrência e a gravidade das manifestações patológicas dos blocos dos empreendimentos. Nos mesmos quadros também foi destacada a porcentagem de prédios em que foram detectadas essas manifestações patológicas. É importante salientar que quanto menor a média, menor é o impacto detectado na falha avaliada e, portanto, melhor a qualidade do sistema avaliado.

\section{Comparação entre diferentes subgrupos de idades de uso}

A seguir, é apresentada a distribuição do tamanho da amostra do grupo relacionado à idade de uso dos empreendimentos avaliados. O primeiro subgrupo de idade, com menos de 4 anos de uso, está constituído por 39 prédios, representando $41 \%$ do tamanho da amostra. O segundo subgrupo de idade, entre 4 anos a menos de 6 anos de uso, está composto por 25 prédios (26\% do tamanho da amostra). E o último subgrupo, de 6 anos ou mais de uso, está constituído por 32 prédios e representa 33\% do tamanho da amostra total. O Quadro 4 apresenta as médias de impacto das manifestações patológicas que mais se destacaram em relação às diferenças estatísticas encontradas entre os subgrupos dos prédios com diferentes idades de uso. 
Quadro 4 - Diferenças nas médias de impacto das manifestações patológicas por idade

\begin{tabular}{|c|c|c|c|c|c|c|}
\hline $\begin{array}{l}\text { Manifestações/ } \\
\text { Idade }\end{array}$ & $\begin{array}{c}\text { Subgrupo } 1 \\
\text { De } 0 \text { a } 3.99 \\
\text { anos } \\
\end{array}$ & $\begin{array}{c}\text { Subgrupo } 2 \\
\text { De } 4 \text { a } 5.99 \\
\text { anos } \\
\end{array}$ & $\begin{array}{c}\text { Subgrupo } 3 \\
\text { De } 6 \text { anos } \\
\text { ou mais } \\
\end{array}$ & Ajuste & P-valor & $\begin{array}{c}\% \\
\text { detectado } \\
\text { da falha } \\
\end{array}$ \\
\hline $\begin{array}{c}\text { Fissuras } \\
\text { mapeadas }\end{array}$ & $20,94^{a}$ & $4,86^{b}$ & $29,20^{a}$ & Gamma & $<0,0001 *$ & 70,83 \\
\hline $\begin{array}{l}\text { Umidade de } \\
\text { Infiltração }\end{array}$ & $15,92^{\mathrm{ab}}$ & $8,30^{b}$ & $18,68^{a}$ & KW & $0,0028 *$ & 84,37 \\
\hline $\begin{array}{c}\text { Sujidade no } \\
\text { topo dos prédios }\end{array}$ & $12,19^{b}$ & $7,36^{b}$ & $36,20^{a}$ & KW & $0,005^{*}$ & 75,00 \\
\hline $\begin{array}{c}\text { Sujidade abaixo } \\
\text { das janelas }\end{array}$ & $6,77^{c}$ & $16,91^{\mathrm{b}}$ & $37,55^{a}$ & Gamma & $<0,0001 *$ & 72,92 \\
\hline Fantasmas & $25,11^{a}$ & $6,24^{b}$ & $13,53^{\text {ab }}$ & Gamma & 0,015* & 51,04 \\
\hline
\end{tabular}

Nota: ${ }^{a}$, b, ce d Sequência de letras que representam da maior a menor média. Letras iguais não diferem significativamente entre si pelos testes de comparações múltiplas a uma significância de $5 \%$

Existem diferentes tipos de fissuras avaliadas neste estudo, porém somente uma delas, "Fissuras Mapeadas”, apresentou diferenças significativas com relação à média de impacto entre os diferentes subgrupos analisados. O Quadro 4 mostra, na coluna de manifestações patológicas, "Fissuras mapeadas", cuja maior média de impacto apresenta-se no subgrupo de maior idade (subgrupo 3). Porém, não foram detectadas diferenças significativas entre os subgrupos de menor e maior idade. Essa diferença somente é observada entre o subgrupo 3 (subgrupo de maior idade) e subgrupo 2 (subgrupo de média idade). Pode-se inferir que o subgrupo mais antigo em idade deveria apresentar menor qualidade no que se refere a esta manifestação patológica (fissuras mapeadas), mas não há diferenças significativas em relação ao subgrupo de prédios com menos idade, o que pode estar relacionado ao fato de que o número de prédios com esta manifestação patológica é pequeno. Da mesma forma, na manifestação patológica "Umidade de infiltração" também não se detectaram diferenças significativas entre os subgrupos de maior e menor idade. Já com relação às manifestações patológicas de "Sujidade no topo dos prédios" e "Sujidade abaixo das janelas" destacam-se no subgrupo de maior idade, as maiores médias. Ao contrário dos dois exemplos anteriores, neste caso existem diferenças significativas entre os subgrupos de maior e menor idade. A Figura 16 apresenta fachadas com sujidade no topo e abaixo das janelas de prédios com mais de 6 anos de uso.

A única manifestação patológica que teve uma maior média de impacto no subgrupo de menor idade foi a manifestação de "Fantasmas". Esse resultado pode estar relacionado ao fato de que este subgrupo apresenta o maior número de prédios com este tipo de problema como é apresentado na análise entre construtoras (Quadro 5). Pode-se então concluir que se não se têm em conta as diferenças significativas entre os subgrupos das manifestações patológicas avaliadas, é possível afirmar que a grande maioria de manifestações nas quais se observou a maior média de impacto foi nos subgrupos de maior idade. Isso está associado ao fato de que quanto mais velho o empreendimento, maior tende a ser o impacto detectado na falha observada, porque as manifestações patológicas vão ficando mais evidentes com o passar do tempo. Esse problema tende a ser mais acentuado em situações nas quais não é feita manutenção adequada das edificações, como no caso da amostra estudada.

\section{Comparação entre empresas construtoras}

Na análise estatística do grupo de construtoras responsáveis pela execução da obra foi feita uma divisão em 4 subgrupos (ou construtoras):

(a) construtora "M" com 5 prédios na amostra;

(b) construtora "L" com 27 prédios;

(c) construtora "N" com 25 blocos; e

(d) construtora "O" com 39 prédios.

No Quadro 5 apresentam-se as médias de impacto de 5 manifestações patológicas avaliadas nas fachadas dos prédios dessas construtoras. Essas manifestações patológicas foram escolhidas por apresentar diferenças significativas entre os empreendimentos avaliados. 
Figura 16 - Sujidade no topo e abaixo das janelas de prédios com mais de 6 anos de uso
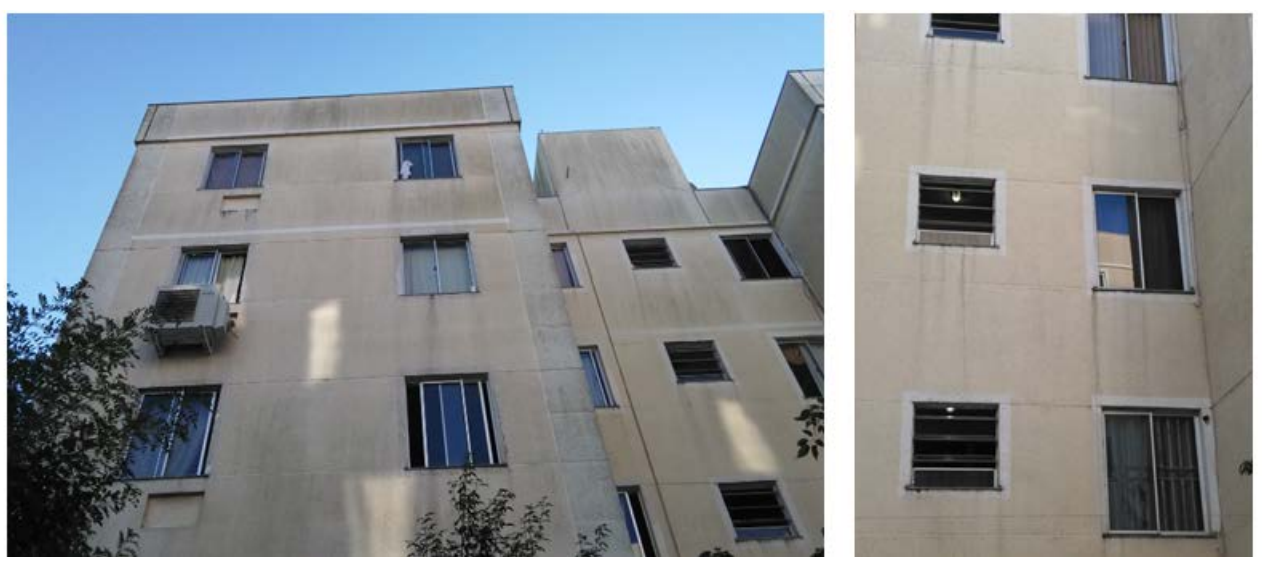

Quadro 5 - Diferenças nas médias de impacto das manifestações patológicas por construtora

\begin{tabular}{|c|c|c|c|c|c|c|c|}
\hline $\begin{array}{c}\text { Manifestações/ } \\
\text { Construtora }\end{array}$ & $\mathbf{M}$ & $\mathbf{L}$ & $\mathbf{N}$ & $\mathbf{O}$ & Ajuste & P-valor & $\begin{array}{c}\% \\
\text { detectado } \\
\text { da falha }\end{array}$ \\
\hline Fissuras mapeadas & $9,84^{\mathrm{ab}}$ & $25,0^{a}$ & $27,04^{a}$ & $10,96^{b}$ & Gamma & 0,0038* & 70,83 \\
\hline $\begin{array}{l}\text { Sujidade pela } \\
\text { improvisação de } \\
\text { instalações e } \\
\text { equipamentos }\end{array}$ & $15,13^{a b}$ & $3,98^{d}$ & $13,00^{\mathrm{abc}}$ & $19,28^{a}$ & Gamma & $<0,0001^{*}$ & 86,46 \\
\hline $\begin{array}{l}\text { Sujidade no topo dos } \\
\text { prédios }\end{array}$ & $9,30^{\mathrm{ab}}$ & $12,10^{\mathrm{a}}$ & $4,10^{b}$ & $22,73^{a}$ & KW & 0,0159* & 75,00 \\
\hline $\begin{array}{l}\text { Sujidade abaixo das } \\
\text { janelas }\end{array}$ & $4,69^{b}$ & $5,12^{b}$ & $3,75^{b}$ & $26,10^{a}$ & Gamma & $<0,0001 *$ & 72,92 \\
\hline Fantasmas & $16,51^{\text {ab }}$ & $40,38^{a}$ & $3,12^{\mathrm{c}}$ & $15,55^{b}$ & Gamma & $<0,0001 *$ & 51,04 \\
\hline
\end{tabular}

Nota: ${ }^{a}$ b, c edSequência de letras que representam da maior a menor média. Letras iguais não diferem significativamente entre si pelos testes de comparações múltiplas a uma significância de $5 \%$

A primeira manifestação patológica analisada neste grupo foi "Fissuras mapeadas”. As empresas construtoras "L" e "N" apresentaram as maiores médias, sendo detectada uma diferença entre essas duas com relação à construtora “O”. Porém, não foi identificada diferença com relação à empresa "M”, possivelmente devido ao fato desta apresentar um número menor de prédios avaliados. As manifestações patológicas "Sujidade pela improvisação de instalações e equipamentos”, "Sujidade no topo dos prédios” e "Sujidade abaixo das janelas" também apresentaram diferenças significativas entre as construtoras. A construtora "O” destaca-se por apresentar as maiores médias de impacto, se comparada às demais. Isto indica que essa é a construtora com o menor nível de qualidade com relação às manifestações avaliadas. Dentre os cinco itens analisados, a construtora "O" apresentou incidência significativamente maior em três dessas falhas. No que se refere à manifestação patológica "Fantasmas” houve uma alta incidência na construtora "L”, com um grau médio de impacto estimado de 40.38, com diferenças significativas em relação com as construtoras "O” e "N". Cabe considerar, que a totalidade dos prédios da construtora " $L$ " fazem parte também do subgrupo de menor idade (prédios com menos de 4 anos de uso) analisado no item anterior. Por essa razão, a manifestação patológica "Fantasmas" apresenta a maior média de impacto nesse subgrupo e não no subgrupo de maior idade como foi mencionado anteriormente, devido, provavelmente, à alta porosidade do revestimento de argamassa o que produz absorção diferenciada de umidade na fachada avaliada. A Figura 17 apresenta alguns prédios com menos de 4 anos de ocupação da construtora "L” afetados pela manifestação “Fantasmas". 
Figura 17 - Prédios com manifestação “Fantasmas” na empresa L
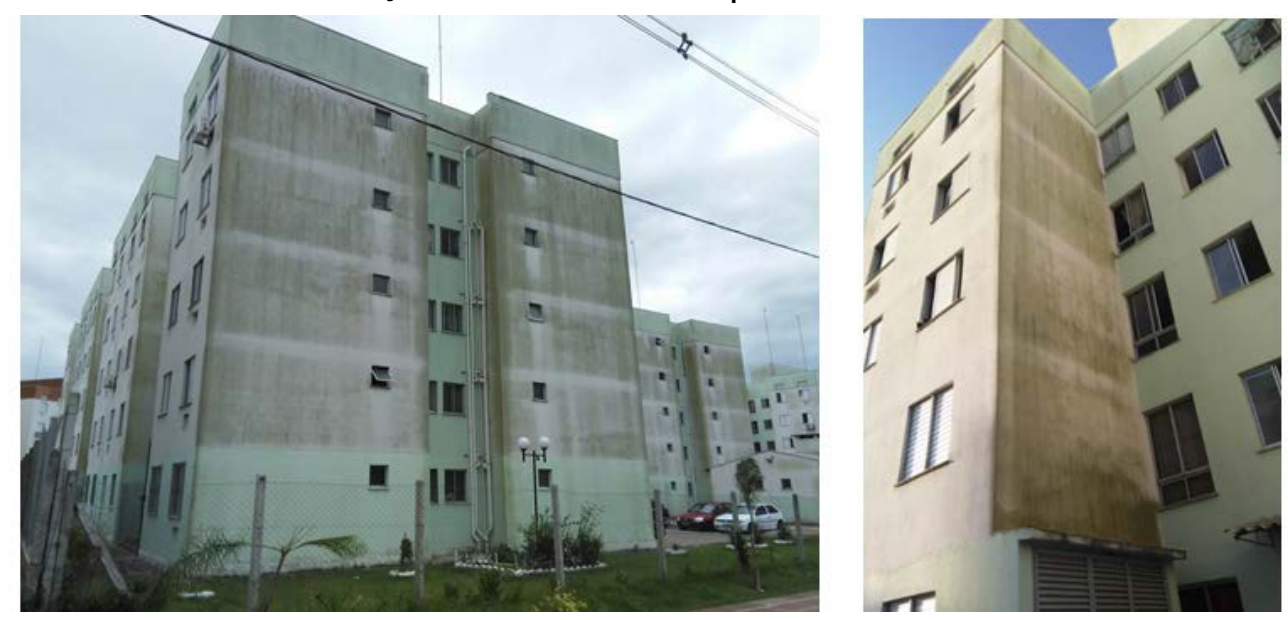

\section{Avaliação do método}

De acordo com March e Smith (1995), em Design Science Research, o artefato desenvolvido deve ser avaliado com base em critérios de utilidade, além de ser uma solução aplicável e funcional na prática. Em relação à utilidade o artefato deve produzir informações para a retroalimentação do processo de construção de EHIS, e também para apoiar a tomada de decisão relativa à recuperação das falhas apresentadas nos empreendimentos. Foram definidos dois critérios para avaliar a utilidade do método: comparação de resultados entre grupos, e auxílio na tomada de decisão.

No que se refere à avaliação dos empreendimentos propriamente dita, é possível identificar pontos fortes e fracos das áreas comuns avaliadas, referentes ao cumprimento ou não de requisitos de norma e ao impacto da qualidade das manifestações patológicas sobre as mesmas áreas comuns.

Com relação à comparação de resultados entre grupos de empreendimentos, demonstrou-se a possibilidade de realizar algumas comparações relevantes, tais como entre diferentes regiões dos empreendimentos, tipologias, faixas de renda, e empresas construtoras. Com respeito às escalas de medição da qualidade das manifestações patológicas o indicador de impacto das falhas permite diferentes priorizações, considerando a frequência e gravidade. Além disto, alguns dados obtidos nas avaliações podem ser usados como indicadores de visibilidade, como, por exemplo, verificar lacunas na aplicação das normas de desempenho e acessibilidade, indicando a necessidade de investigações mais aprofundadas sobre a aplicação dos requisitos delas. Nas entrevistas com engenheiros da Caixa Econômica Federal (CEF). foi apontada a importância de utilizar o conjunto de requisitos de norma com a finalidade de identificar quais empresas construtoras estão entregando obras em conformidade com relação aos requisitos exigidos pelas normas vigentes.

Com relação à facilidade de uso, foi analisado o esforço envolvido na aplicação do método, bem como na interpretação dos dados obtidos. Com relação ao tempo de coleta de dados, em média foram dispendidas 3h30min por empreendimento, sendo que em torno de 20 min eram referentes às questões respondidas pelo síndico do condomínio; em torno de 65 min eram dedicados às observações técnicas referentes às áreas de uso comum do condomínio (estacionamentos e calçadas); e em torno de 125 min para as áreas comuns dos prédios do condomínio, tais como circulações internas e fachadas. Com relação à facilidade de intepretação dos dados, o método foi avaliado e refinado por meio de entrevistas com oito professores, pesquisadores da área do ambiente construído, e três engenheiros da Caixa Econômica Federal.

Por fim, no que se refere às limitações do método, pode-se apontar que o método tem um certo grau de subjetividade na definição índices de ocorrência e de gravidade das falhas, que pode ocorrer pela diferença de experiência entre um avaliador e outro no momento da mensuração dos índices em uma manifestação patológica. Por outro lado, para avaliar o atendimento dos requisitos das normas o grau de subjetividade é muito menor. Assim, existem oportunidades de refinamento dos critérios utilizados na definição dos índices, particularmente no caso do índice de gravidade das manifestações patológicas. Este tipo de refinamento requer estudos aprofundados, específicos para cada tipo de manifestação patológica.

Outra limitação nesta pesquisa foi o tamanho da amostra, que reduziu as possibilidades de análises estatísticas feitas nos subgrupos, e pode ter influenciado a não identificação de diferenças significativas. Entretanto, essa 
limitação não prejudica os resultados da pesquisa, cujo objetivo foi desenvolver e testar a utilidade e aplicabilidade do método.

\section{Conclusões}

O presente artigo propôs um método para avaliar a qualidade pós-ocupação de áreas comuns de empreendimentos habitacionais de interesse social sob uma perspectiva técnica, a partir de observações diretas, realizadas de forma rápida e sistemática pelo avaliador. As informações coletadas nessas observações são feitas de forma padronizada possibilitando análises consistentes das avaliações e comparações entre diferentes empreendimentos. Foi necessária a criação de escalas de medição para avaliar a qualidade das áreas de uso comum. Os requisitos das normas foram avaliados por meio de escala de escolha simples, a qual é utilizada para avaliar o atendimento ou não desses requisitos. Já para avaliar as manifestações patológicas foi necessária a criação de dois índices: o índice de ocorrência da falha e o índice de gravidade da falha. Com base nos resultados obtidos na aplicação do método, é possível apontar pontos fracos e fortes das áreas comuns avaliadas e identificar as manifestações patológicas com maior impacto sobre o sistema estudado. De acordo com Santos et al. (2017), é importante identificar o quanto antes o surgimento das manifestações patológicas, para evitar o aparecimento de novas manifestações decorrentes das primeiras e assim impedir que estas possam afetar a segurança do sistema avaliado.

O método pode ser utilizado por diferentes intervenientes de EHIS, interessados em retroalimentar os processos de projeto e execução de obras, tais como empresas construtoras, agentes promotores, e órgãos financiadores de EHIS. A partir das informações coletadas, é possível priorizar os problemas de maior impacto, sejam estes não-conformidades em relação às normas ou manifestações patológicas, com base em um índice que combina a frequência e a gravidade dos problemas. Para os órgãos financiadores e promotores dos empreendimentos habitacionais, as informações coletadas pelo método são úteis por permitir diferentes comparações, tais como desempenho de empresas construtoras, faixas de renda dos usuários, localização dos empreendimentos, entre outros. Outra contribuição importante do método refere-se à possibilidade de avaliar a conformidade dos EHIS em relação a requisitos de normas vigentes, com enfoque nas áreas comuns, a norma de desempenho (ABNT, 2013a) e de acessibilidade (ABNT, 2015).

Como sugestões de trabalhos futuros relacionados com o tema proposto no presente artigo, pode-se apontar, estudos com o tamanho da amostra de EHIS ampliada, com a finalidade de explorar outras possíveis correlações entre variáveis. Por exemplo, poderiam ser feitas análises sobre a incidência de algumas patologias em relação à orientação solar das fachadas dos edifícios, ou práticas de manutenção diferenciadas entre diferentes condomínios. Além disso, é recomendável o desenvolvimento de aplicativos, de forma a facilitar a coleta de dados, seu processamento e armazenamento das informações resultantes. Outra oportunidade de estudo futuro é o aumento do escopo de itens a avaliar, tanto em termos de requisitos de norma, como de manifestações patológicas e de áreas de uso comum. Por fim, recomenda-se estender o método proposto para outros sistemas e tipologias construtivas, em contextos diferentes daqueles considerados neste trabalho.

\section{Referências}

ALEXANDRE, I. F. Manifestações patológicas em empreendimentos habitacionais de baixa renda executados em alvenaria estrutural: uma análise da relação de causa e efeito. Porto Alegre, 2008. Dissertação (Mestrado em Engenharia Civil) - Programa de Pós-Graduação em Engenharia Civil, Universidade Federal do Rio Grande do Sul, Porto Alegre, 2008.

ASSOCIAÇÃO BRASILEIRA DE NORMAS TÉCNICAS. NBR 15575-1: edificações habitacionais: desempenho: parte 1: requisitos gerais. Rio de Janeiro, 2013a.

ASSOCIAÇÃO BRASILEIRA DE NORMAS TÉCNICAS. NBR 15575-3: edificações habitacionais: desempenho: parte 3: requisitos para os sistemas de pisos. Rio de Janeiro, 2013b.

ASSOCIAÇÃO BRASILEIRA DE NORMAS TÉCNICAS. NBR 15575-4: edificações habitacionais: desempenho: parte 4: requisitos para os sistemas de vedações verticais internas e externas - SVVIE. Rio de Janeiro, 2013c.

ASSOCIAÇÃO BRASILEIRA DE NORMAS TÉCNICAS. NBR 15575-5: edificações habitacionais: desempenho: parte 5: requisitos para os sistemas de coberturas. Rio de Janeiro, 2013d.

ASSOCIAÇÃO BRASILEIRA DE NORMAS TÉCNICAS. NBR 9050: acessibilidade a edificações, mobiliário, espaços e equipamentos urbanos. Rio de Janeiro, 2015. 
BERR, L. R. et al. Indicador de falhas de qualidade baseado na percepção dos usuários de Habitação de Interesse Social. Ambiente Construído, Porto Alegre, v. 15, n. 4, p. 19-35, out./dez. 2015.

BERR, L. R. Método de avaliação da qualidade construtiva de unidades habitacionais de interesse social na etapa de uso: análise técnica e percepção dos usuários. Porto Alegre, 2016. Tese (Doutorado em Engenharia Civil) - Programa de Pós-Graduação em Engenharia Civil, Universidade Federal do Rio Grande do Sul. Escola de Engenharia, Porto Alegre, 2016.

BORGES, C. A. de M. O conceito de desempenho de edificações e a sua importância para o setor da construção civil no Brasil. São Paulo, 2008. Dissertação (Mestrado em Engenharia Civil) - Escola Politécnica, Universidade de São Paulo, São Paulo, 2008.

BRITO, J. N. S. et al. Análise de dados de reclamações em empreendimentos Habitacionais de Interesse Social: estudo no Programa de Arrendamento Residencial. Ambiente Construído, Porto Alegre, v. 11, n. 4, p. 151-166, out./dez. 2011.

DAL MOLIN, D. C. C. Contribuição à previsão da vida útil de estruturas de concreto. In: KAZMIERCZAK, C. de S.; FABRÍCIO, M. M. (Org.). avaliação de desempenho de tecnologias construtivas inovadoras: materiais e sustentabilidade. São Carlos: Editora Scienza, 2016.

DEL MAR, C. P. Falhas, responsabilidades e garantias na construção civil. São Paulo: PINI, 2013.

DRESCH, A. Design science e design science research como artefatos metodológicos para engenharia de produção. São Leopoldo, 2013. Dissertação (Mestrado em Engenharia Civil) - Programa de Pósgraduação em Engenharia de Produção e Sistemas, Universidade do Vale do Rio dos Sinos, São Leopoldo, 2013.

DUARTE, R. B. Fissuras em alvenaria: causas principais, medidas preventivas e técnicas de recuperação. Porto Alegre, 1998. CIENTEC - Boletim técnico n. 25.

FIGUEIREDO, A. et al. manifestações patológicas identificadas em um edifício residencial de alvenaria resistente em Recife (PE). In: CONFERÊNCIA NACIONAL DE PATOLOGIA E RECUPERAÇÃO DE ESTRUTURAS, Recife, 2017. Anais... Recife, 2017.

GEORGIOU, J. Verification of a building defect classification system for housing. Structural Survey, v. 28, n. 5, p. 370-383, 2010.

GOOGLE MAPS. [Empreendimentos selecionados na Região Metropolitana de Porto Alegre, RS]. Disponível em: https://www.google.com.br/maps/@-29.9054388,-50.9642156,10.75z. Acesso em: 24 maio 2018.

HELMAN, H.; ANDERY, P. R. P. Análise de falhas: aplicação dos métodos de FMEA-FTA. Belo Horizonte: Fundação Christiano Ottoni, Escola de Engenharia da UFMG, 1995.

HEVNER, A. R. et al. Design science in information systems research. MIS Quarterly, v. 28, n. 1, p. 75105, 2004.

HOLANDA JÚNIOR, O. G. Influência de recalques em edifícios de alvenaria estrutural. São Carlos, 2002. Tese (Doutorado em Engenharia Civil) - Escola de Engenharia de São Carlos, Universidade de São Paulo, São Carlos, 2002.

KOSKELA, L. Application of the new production philosophy to construction. Center for Integrated Facility Engineering, Stanford University, Stanford, 1992. Technical Report n. 72.

LIMA, P. R. B. Consideração do projeto no desempenho dos sistemas construtivos e qualidade da edificação: proposição de um modelo de banco de dados. Belo Horizonte, 2005. Dissertação (Mestrado em Engenharia Civil) - Escola de Engenharia, Universidade Federal de Minas Gerais, Belo Horizonte, 2005.

MARCH, S. T.; SMITH, G. F. Design and natural science research on information technology. Decision Support Systems, v. 15, n. 4, p. 251-266, 1995.

MARQUES, L. M. Minha Casa Minha Vida: análise de percepção de valor sobre as áreas comuns. Porto Alegre, 2015. Dissertação (Mestrado em Engenharia Civil) - Faculdade de Arquitetura, Universidade Federal do Rio Grande do Sul, Porto Alegre, 2015.

MELO JUNIOR, C. M. Influência da chuva dirigida e dos detalhes arquitetônicos na durabilidade de revestimentos de fachada. Goiânia, 2010. Dissertação (Mestrado em Engenharia Civil) - Escola de Engenharia, Universidade Federal de Goiás, Goiânia, 2010. 
PETRUCCI, H. M. C. A Alteração da aparência das fachadas dos edifícios: interação entre as condições ambientais e a forma construída. Porto Alegre, 2000. Dissertação (Mestrado em Engenharia Civil) - Escola de Engenharia, Universidade Federal do Rio Grande do Sul, Porto Alegre, 2000.

POYASTRO, P. C. Influência da volumetria e das condições de entorno da edificação no manchamento e infiltração de água em fachadas por ação de chuva dirigida. Porto Alegre, 2011. Dissertação (Mestrado em Engenharia Civil) - Escola de Engenharia, Universidade Federal do Rio Grande do Sul, Porto Alegre, 2011.

RESENDE, M. M. Manutenção preventiva de revestimentos de fachada de edifícios: limpeza de revestimentos cerâmicos. São Paulo, 2004. Dissertação (Mestrado em Engenharia Civil) - Escola Politécnica, Universidade de São Paulo, São Paulo, 2004.

RICHTER, C. Qualidade da alvenaria estrutural em habitações de baixa renda: uma análise da confiabilidade e da conformidade. Porto Alegre, 2007. Dissertação (Mestrado em Engenharia Civil) - Escola de Engenharia, Universidade Federal do Rio Grande do Sul, Porto Alegre, 2007.

SANTOS, C. R. B. dos; SILVA, D. L. da; NASCIMENTO, I. M. S. do. Incidência de manifestações patológicas em edificações residenciais na região metropolitana do Recife (RMR). Revista de Engenharia e Pesquisa Aplicada, v. 2, n. 3, 2017.

SEGAT, G. T. Manifestações patológicas observadas em revestimentos de argamassa: estudo de caso em conjunto habitacional popular na cidade de Caxias do Sul (RS). Trabalho de Conclusão (Mestrado profissional) - Escola de Engenharia, Universidade Federal do Rio Grande do Sul, Porto Alegre, 2006.

VAN AKEN, J. E. Management research based on the paradigm of the design sciences: the quest for fieldtested and grounded technological rules. Journal of Management Studies, v. 41, n. 2, p. 219-246, 2004.

YUNG, P.; YIP, B. Construction quality in china during transition: a review of literature and empirical examination. International Journal of Project Management, v. 28, n. 1, p. 79-91, 2010.

ZANINI, C. M. Elaboração de um instrumento e avaliação de segurança em calçadas. Porto Alegre, 2017. Dissertação (Mestrado em Engenharia Civil) - Escola de Engenharia, Universidade Federal do Rio Grande do Sul, Porto Alegre, 2017.

ZUCCHETTI, L. Influência das características do peitoril no molhamento dos paramentos próximos às janelas frente à chuva dirigida. Porto Alegre, 2016. Tese (Doutorado em Engenharia Civil) - Escola de Engenharia, Universidade Federal do Rio Grande do Sul, Porto Alegre, 2016.

\section{Pablo Andrés Rangel}

Escola de Engenharia, Programa de Pós-Graduação em Engenharia Civil: Construção e Infraestrutura | Universidade Federal do Rio Grande do Sul | Av. Osvaldo Aranha, 99, 70 andar | Porto Alegre - RS - Brasil | CEP 90035-190 | Tel.: (51) 3308-4848 | E-mail: pablorangelp@gmail.com

\section{Carlos Torres Formoso}

Escola de Engenharia, Programa de Pós-Graduação em Engenharia Civil: Construção e Infraestrutura | Universidade Federal do Rio Grande do Sul | E-mail: formoso@ufrgs.br

\section{Luciana Inês Gomes Miron}

Departamento de Arquitetura | Universidade Federal do Rio Grande do Sul | Av. Sarmento Leite, 320, sala 516 | Porto Alegre - RS - Brasil | CEP 90050-170 | Tel.: (51) 3308-3124 | E-mail: luciana.miron@ufrgs.br

\section{Márcia Elisa Soares Echeveste}

Departamento de Estatística, Programa de Pó-Graduação em Engenharia de Produção | Universidade Federal do Rio Grande do Sul | Rua Osvaldo Aranha, 99 | Porto Alegre - RS - Brasil | CEP 90035-190 | Tel.: (51) 3308-1986| E-mail: echeveste@producao.ufrgs.br

\section{Ambiente Construído}

Revista da Associação Nacional de Tecnologia do Ambiente Construído

Av. Osvaldo Aranha, 99 - 3o andar, Centro

Porto Alegre - RS - Brasil

CEP $90035-190$

Telefone: +55 (51) 3308-4084

Fax: +55 (51) 3308-4054

www. seer. ufrgs. br/ ambienteconstruido

E-mail: ambienteconstruido@ufrgs.br

This is an open-access article distributed under the terms of the Creative Commons Attribution License. 